\title{
Migrating Curlews on Schedule: Departure and Arrival Patterns of a Long-Distance Migrant Depend on Time Rather than on Wind Conditions
}

Philipp Schwemmer ( $\nabla$ schwemmer@ftz-west.uni-kiel.de )

Research and Technology Centre (FTZ), University of Kiel https://orcid.org/0000-0002-3930-2845 Moritz Mercker

Bionum $\mathrm{GmbH}$ - Consultants for biological statistics

Klaus Heinrich Vanselow

Research and Technology Centre (FTZ), University of Kiel

\section{Pierrick Bocher}

Littoral Environnement et Sociétés Laboratory (LIENSs), University of La Rochelle

\section{Stefan Garthe}

Research and Technology Centre (FTZ), University of Kiel

\section{Research}

Keywords: shorebird, Wadden Sea, flight altitude, phenology, GPS tracking, repeatability

Posted Date: November 9th, 2020

DOl: https://doi.org/10.21203/rs.3.rs-101849/v1

License: (c) (i) This work is licensed under a Creative Commons Attribution 4.0 International License. Read Full License 


\section{Abstract}

Background: Choosing the appropriate time to depart for spring migration is crucial to achieving a successful subsequent breeding season among migratory bird species. We expected Eurasian Curlews (Numenius arquata) to start their migration during favourable weather conditions and to adjust their flight heights to prevailing wind conditions.

Methods: We equipped 23 curlews with Global Positioning System data loggers to record the spatiotemporal patterns of their departure from and arrival at their wintering site in the Wadden Sea, as well as the first part of their migration. We obtained data for 42 curlew migrations over a period of 6 years. Departure and arrival dates were related to 73 meteorological and bird-related predictors using the least absolute shrinkage and selection operator (LASSO) to identify drivers of departure and arrival decisions.

Results: Curlews migrated almost exclusively to the western part of Russia for breeding. They left the Wadden Sea mainly during the evening hours from mid- to late April and returned between the end of June and mid-July. There was no difference in departure times between the sexes, but males tended to return from their breeding sites later than females. Flight speeds of the birds increased significantly with increasing tailwind component, suggesting that they timed their migration according to favourable wind conditions. However, curlews left the Wadden Sea during various wind and weather conditions, with significant numbers leaving during headwind conditions, in contrast to the apparent wind-driven start of migration. Curlews migrated at very low altitudes during tailwind conditions, but flew significantly higher during headwind conditions, at altitudes of up to several kilometres. Departure dates varied by $<4$ days in individual curlews that were tagged over consecutive years.

Conclusions: Our results suggest that the start of migration in a long-distance migrant mainly depends on the date and is independent of weather conditions. Given the high repeatability of the departure day among subsequent years, this clearly suggests the existence of an internal clock prompting the start of migration. Further insights into the timing of migration in immatures and closely related birds might help us to understand the genetic mechanisms triggering temporal migration patterns.

\section{Background}

Migration is an essential part of the life cycle of a wide range of species, with potentially important consequences for their fitness [1-5]. Birds show the most extensive and far-ranging migrations [6-8]. Careful timing of migration is essential to maximize the chance of survival during migration (e.g. to avoid severe weather) $[9-12,5]$ and to coincide with beneficial environmental resources in the destination areas, as a prerequisite to ensuring fitness [13-14].

We studied the departure and arrival patterns of a long-distance migrating shorebird, the Eurasian Curlew (Numenius arquata), at one of its most important wintering sites on the East Atlantic Flyway, the Wadden Sea. Despite strong population decreases in the flyway population as a whole [15], the numbers of curlews wintering in the Wadden Sea have remained stable for several decades [16]. The Wadden Sea 
population holds around $200,000-260,000$ individuals, accounting for around $40 \%$ of the total flyway population [16-17]. However, information on the migration patterns of curlews wintering in the Wadden Sea is scarce (but see [18] for a preliminary study). A previous study from south-west England investigated the arrival and departure patterns of curlews based on a dataset of re-sightings of colourmarked individuals [19]. In the current study, we equipped curlews with Global Positioning System (GPS) data loggers that recorded the times of arrival and departure of each individual bird in the Wadden Sea. This allowed individual departure and arrival patterns to be precisely related to meteorological data, and allowed the repeatability of temporal patterns across subsequent years to be assessed. We proposed the following five hypotheses. (1) Tailwinds increase flight and migration speeds [6;20-21], and we therefore expected a positive linear relationship between flight speed and tailwind components (TWC). (2) Individuals of a range of bird species have been shown to time their departure according to favourable wind and weather conditions (e.g. a tailwind and no or little precipitation; [12, 22-24]. In line with our first hypothesis, we therefore expected curlews to time their departure from and arrival at their wintering grounds according to favourable wind and weather conditions, especially in relation to tailwind conditions and lack of precipitation. (3) We expected flight heights (as recorded by GPS tags) to increase during non-tailwind conditions to allow the birds to reach air layers with improved wind conditions [2526]. (4) We hypothesized that birds breeding further from their wintering site would depart earlier because they needed more time for travelling. In this context, we expected males to arrive at the wintering sites later than female curlews, because, as for other shorebird species, females are known to desert their chicks earlier than males [27]. (5) Finally, we predicted significant effects of departure date and tailwind component on the distance to and duration of the first stop-over event. Curlews departing later were expected to stop-over for only a short period of time and then continue quickly to their breeding grounds [23]. Previous studies indicated that headwind conditions could significantly shorten the distance to the first migration stop-over and increase the stop-over duration to allow birds to refuel before continuing [e.g. 28].

In the current study, we analysed data for tagged curlews from the Wadden Sea area over multiple years and extended the preliminary GPS-tagging study presented in [18].

\section{Methods}

\section{Study area}

Curlews were caught along the eastern Wadden Sea coast of the German federal states of SchleswigHolstein and north-eastern Lower Saxony between $54^{\circ} 36^{\prime} \mathrm{N}$ and $53^{\circ} 42^{\prime} \mathrm{N}$, and between $7^{\circ} 54^{\prime} \mathrm{E}$ and $8^{\circ} 54^{\prime} \mathrm{E}$ (Fig. 1). Meteorological parameters were recorded by the automatic recording station of the Research and Technology Centre, located in Büsum, federal state of Schleswig-Holstein $\left(54^{\circ} 7 \times 55^{\prime \prime} \mathrm{N} ; 8^{\circ} 52 \times 37^{\prime \prime} \mathrm{E}\right.$; yellow circle in Fig. 1). Flight speeds and altitudes of GPS-tagged individuals were recorded within an area stretching from the Wadden Sea coast to the Baltic Sea and from south Denmark to the northern part of the federal State of Lower Saxony (red box in Fig. 1). 


\section{Catching of curlews and deployment of GPS tags}

A total of 26 adult curlews were caught at their high-tide roosts using mist nets, between 2014 and 2020 . Three of the GPS devices malfunctioned or the birds were predated before departure from their wintering grounds, and data for 23 adult wintering curlews ( 11 females and 12 males) were therefore available for this study. Some curlews migrated multiple times before the device stopped working, and we were therefore able to record the departures and arrivals of the same individuals in up to 5 subsequent years. We recorded a total of 42 departures from and 33 arrivals at the wintering sites. All individuals were equipped with solar-powered GPS-Global System for Mobile Communications (GSM) data loggers attached by breast harnesses $[18,29]$. The devices recorded time, date, geographical position, and flight speed at pre-programmed intervals of 1-15 min. Twelve individuals were equipped with "Skua" data loggers (Ecotone, Poland) weighing $17 \mathrm{~g}$, and the other 11 individuals were equipped with OT-20 (3 individuals), OT-15 (7 individuals), and OT-10 (1 individual) data loggers, weighing 20, 15, and $10 \mathrm{~g}$, respectively (Ornitela, Lithuania). Our study took place over a period of 7 years and we therefore aimed to use progressively lighter data loggers in line with technical developments (particularly logger weight reduction) over this time period. The mean body masses of female and male curlews were $957.7 \pm 74.3 \mathrm{~g}$ and $827.8 \pm 92.1 \mathrm{~g}$, respectively. Even the heaviest data loggers used in this study therefore accounted for only about $2.4 \%$ of body mass, which was below the threshold of $3 \%$ suggested to avoid confounding effects of the devices [30]. The Skua devices only sent part of the data to a server via a GSM connection, which could then be downloaded directly, and the rest of the data were transmitted to base stations set up next to the high-tide roosts. The full dataset for the Skua devices was thus only obtained after the birds had returned to their wintering sites in the Wadden Sea. The highest temporal resolution achieved by these devices was $15 \mathrm{~min}$. In contrast, the OT devices transmitted the whole dataset to an online portal, and the recording intervals were programmed according to a flexible schedule, generally ranging from 1-15 min, based on the battery status of the device. We programmed "geofences" (i.e. defined areas in which the devices recorded data constantly in 1-min intervals) for all OT devices. The geofence covered the red box shown in Fig. 1, but excluded high-tide roosts, to save battery power. The high temporal resolution of the GPS fixes allowed flight height measurements to be derived within the red box area shown in Fig. 1, and also further east.

All data recorded by the GPS devices were finally stored in the online portal Movebank (www.movebank.org).

In addition to equipping each bird with a GPS device, all individuals were ringed and weighed, bill and wing lengths were measured, age was determined, and sex was determined by taking a breast feather for genetic sexing in the lab (Tauros Diagnostics, Berlin).

\section{Data analyses}

We visualized the GPS data for each curlew using the Geographical Information System ArcGIS (version 10.3) [31]. The time (UTC) and day of the year at which the birds left their wintering grounds heading north-east towards their breeding sites were determined. This departure was evident from the GPS tracks, 
and was always associated with a clear increase in flight speed (and flight heights in OT devices). The time and day of year of arrival at the wintering grounds was determined in a similar manner.

Meteorological data were recorded at 1-min intervals by an automatic recording station located at the Research and Technology Centre in Büsum, and weather conditions were related to the curlews' departure and arrival patterns (see Statistical analysis section below). The recorded parameters were: temperature $\left({ }^{\circ} \mathrm{C}\right)$, wind speed and maximum wind speed $(\mathrm{m} / \mathrm{s})$, wind direction (degrees), precipitation $(\mathrm{mm})$, global radiation $\left(\mathrm{W} / \mathrm{m}^{2}\right)$, UVA and UVB $\left(\mathrm{W} / \mathrm{m}^{2}\right)$, photosynthetically active radiation $\left(\mathrm{W} / \mathrm{m}^{2}\right)$, air pressure $(\mathrm{mbar})$, and air humidity (\%). For all parameters, we computed the mean values of the 1-min recordings over a period from 90 min before to 90 min after the departure/arrival of each individual curlew. The mean values were then related to the departure/arrival day (see Statistical analysis section below) and used to test for differences in weather conditions between departures and arrivals. To account for the circular nature of the wind direction, means were calculated as the direction of a circular vector using the Rpackage circular [32]. Wind-rose plots of the wind direction during the departure and arrival of curlews were created using the R-package openair [33].

To relate the departure and arrival dates to linear distance from the breeding area, it was necessary to determine the location of the breeding area for each curlew. The likely breeding area was identified in GIS (white triangles in Fig. 4). It could be distinguished from stop-over locations by being the most distant point from the wintering location, and at the same time as a location where the birds stayed for several weeks (more than at each stop-over location) with very limited movement behaviour. The approximate coordinate of the nest site was calculated by computing the mean geographical position of all positions in the potential breeding site. Finally, the linear distance between this position and the wintering site was calculated in GIS.

Departure dates were also related to the linear and flown distances (calculated in GIS) to the first stop (red circles in Fig. 4), the flight time to the first stop, and the duration of the first stop. The same was applied for the arrival dates using the last stop before the wintering site (orange circles in Fig. 4). The mean locations of the nearest stops to the wintering sites were calculated in the same way as for the breeding site. In some cases, birds migrated from their wintering sites in the Wadden Sea to other Wadden Sea areas (always $<30 \mathrm{~km}$ distance), probably to join other birds shortly prior to departure. These locations were not regarded as first stop-over events, and the departure from the last site in the Wadden Sea was used for the analyses instead.

Finally, we computed the relative deviation between the flown and linear distances (\%) as an indicator of the curvature of the actual flight track. This was expected to increase during headwind conditions, because birds might try to avoid headwinds by choosing different flight angles. Only flight tracks with log-intervals of $\leq 5 \mathrm{~min}$ were used for this to keep the flight tracks comparable.

We determined the mean departure direction of each individual across the red box shown in Fig. 1 and related it to the mean recorded wind speed and wind direction to compute the TWC. This is known to have a significant impact on the migration speed of birds [20-21,34], and was therefore expected to affect the 
departure and arrival decisions of the curlews in the current study. According to [35], we used the following formula: TWC $=v \times \cos x$, where $v$ is the wind speed in $\mathrm{ms}^{-1}$ and $x$ is the angular deviation between the opposite flight direction of the curlew (i.e., tailwind direction) and the wind direction (in degrees). In addition to using TWC as an additional predictor of departure and arrival decisions, we also related it to mean flight speed to demonstrate if the birds were able to increase their speed during tailwind conditions, and to mean flight height within the red box in Fig. 1.

\section{Statistical analysis}

All statistical analyses were carried out using the open source software R, version 3.6.3 [36]. Plots were visualized using the R package ggplot2 [37]. All regressions were performed using generalized additive models (GAMs) [38-39] using the R package $m g c v$ [40]. Individual was included as a random intercept in the GAMs to avoid pseudo-replication due to multiple observations of the same individual. For each model, we selected an appropriate probability distribution for the variable of interest; if different probability distributions were reasonable (e.g. in the case of possibly overdispersed count data), we selected the most appropriate distribution based on the Akaike Information Criterion [41].

We related the departure day to meteorological data to see if departure decisions were affected by the weather. We considered the meteorological data under six conditions, including (1) at the moment of departure and (2) the mean conditions $90 \mathrm{~min}$ before to $90 \mathrm{~min}$ after departure. We also contrasted (3) the moment of departure and (4) the mean conditions $90 \mathrm{~min}$ before to $90 \mathrm{~min}$ after departure with the same measure on the 4 days before departure, to determine if curlews experienced suboptimal conditions prior to their departure, which might have delayed their departure decision. Finally, we also contrasted (5) the moment of departure and (6) the mean conditions $90 \mathrm{~min}$ before to $90 \mathrm{~min}$ after departure with the same measure at the same time of day on the same date for the average of the 4 previous years to determine if the curlews experienced suboptimal meteorological conditions compared with the average conditions on similar dates. In all cases, the meteorological conditions were compared by dividing the weather data at the moment of departure (respectively $90 \mathrm{~min}$ before to $90 \mathrm{~min}$ after departure) by the average conditions at the same moment (same time interval) for the 4 preceding days/years. If the meteorological variable of interest had a zero value, the difference was calculated instead of the quotient.

In addition to the above meteorological parameters, we also used the following additional predictors to model the departure decision (defined by day of the year): number of migrations for each individual bird, sex of the individual, catching location in the Wadden Sea, year, time of day, breeding latitude, linear distance to breeding area, departure direction, TWC, time to first stop-over, duration of first stop-over, flown distance to first stop, and linear distance to first stop. For TWC, we used the six different combinations of meteorological data given above. All other predictors were kept constant.

We therefore used a total of 73 predictors to model the departure decision (i.e. 55 constant and contrasted meteorological predictors, 6 constant and contrasted combinations of TWC, and 12 constant predictors related to the individual curlews or the first stop-over event). The same predictors were used to model the arrival of the birds in their wintering grounds. 
The effects of the 73 predictors on day of the year (outcome variable) were tested using the least absolute shrinkage and selection operator (LASSO) [42-43] technique for predictor selection. This technique is known to handle a large number of possible predictors without being prone to statistical problems e.g. compared with stepwise methods (c.f., below). Notably, LASSO has been combined with cross-validation to select promising predictors based on their predictive capacity [42-44]. In contrast to the common stepwise methods (e.g., forward or backward selection procedures), LASSO-based results are not sensitive to the order of the performed tests [44-45]. However, it is necessary to bear in mind that the chance of detecting a significant relationship between a predictor and the considered outcome variable increases with the number of investigated predictors.

\section{Results}

Phenology of departures and arrivals

The first curlew departed from the wintering grounds on April 7 and the last on May 16. Most individuals departed between mid- and late April (Fig. 2). Females tended to depart earlier, but the sex difference was not significant (GAM: $t=1.23, d f=41, p=0.23$ ). The first curlews arrived at the wintering sites on June 3 and the last on July 24, with most birds arriving between mid-June and the end of July (Fig. 2). There was a clear but not significant tendency for females to arrive earlier than males (GAM: $t=1.97, d f=31, p=$ 0.067 ; mean day of year females: $177.9 \pm 13.1$, mean day of year males: $189.9 \pm 11.7$ ).

Departures mainly occurred during the late evening, shortly before sunset, with no significant difference between the sexes (GAM: $t=-0.29, d f=41, p=0.78$; Fig. 3a). The time of day for arrivals differed from that for departures (Table 1, Suppl. 1a), with significantly more arrivals during the nighttime and also occasionally during daytime. As for departing curlews, there was no sex difference in terms of arrivals (GAM: $t=1.7, d f=31, p=0.09 ;$ Fig. 3b). 
Table 1

GAMs comparing migration parameters, and wind variables between departing and arriving curlews.

\begin{tabular}{|c|c|c|c|c|}
\hline & $\begin{array}{l}\text { Estimate } \\
\text { Std. }\end{array}$ & Error & $\begin{array}{l}\mathrm{t}- \\
\text { value }\end{array}$ & $\begin{array}{l}\mathrm{p}- \\
\text { value }\end{array}$ \\
\hline Time of day & -3.08 & 1.32 & -2.33 & 0.023 \\
\hline $\begin{array}{l}\text { Rel. diff. between flown and linear distance to nearest } \\
\text { stop }\end{array}$ & -2.06 & 1.75 & -1.8 & 0.244 \\
\hline Linear distance to nearest stop & -432.4 & 106.2 & -4.07 & $<.001$ \\
\hline Time to nearest stop & -189.47 & 118.16 & -1.6 & 0.114 \\
\hline Duration of nearest stop & 258.7 & 433.5 & 0.6 & 0.553 \\
\hline Mean flight speed & -18.53 & 4.12 & -4.49 & $<.001$ \\
\hline Tail wind component & -0.33 & 0.67 & -0.5 & 0.618 \\
\hline Mean flight altitude & -930.2 & 164.9 & -5.64 & $\begin{array}{l}<.001 \\
0.001\end{array}$ \\
\hline Mean wind speed & -1.29 & 0.45 & -2.89 & 0.005 \\
\hline Mean wind direction & -2.2 & 27.43 & -0.08 & 0.936 \\
\hline
\end{tabular}

[Table 1 should be placed approximately here]

GPS tracks of curlews and relationships with nearest stop-over sites

After their departure from the wintering grounds in the Wadden Sea, all curlews headed towards their breeding sites, which were located exclusively in north-western Russia (except for one individual that was breeding in Finland; see white triangles in Fig. 4). The most distant breeding site was 3,840 km from the wintering site, east of the Ural Mountains. The mean linear distance of all flight tracks was 2,339 \pm $612 \mathrm{~km}$. The relative differences between the flown and linear distances to the breeding sites were similar for arriving and departing curlews (Table 1; Suppl. 1b).

The mean linear distance between the nearest stop-over site and the wintering site for departing curlews was $775.8 \pm 376 \mathrm{~km}$, which represents $33.2 \%$ of the linear distance to their breeding sites (i.e. birds performed about $1 / 3$ of their overall migration during their first migration bout). Curlews selected a straight flight path to reach their first stop-over site, with the distance flown on average only $45.7 \mathrm{~km}$ longer than the linear distance (5.6\%).

Many curlews crossed the Baltic Sea directly, while others stopped over on the Danish islands or the southern Baltic Sea coast (see red circles in Fig. 4). The nearest stop-over site for arriving curlews was significantly closer to the wintering site than that for departing curlews (mean: 342.4 km; Table 1; Suppl. 
$1 \mathrm{c})$, but the distance was highly variable $( \pm 503.1 \mathrm{~km})$. In contrast, both time to the nearest stop-over site and duration of the nearest stop were similar for departing and arriving curlews (Table 1; Suppl. 1d, e).

Finally, there was no significant relationship between flight time to the nearest stop-over and stop-over duration, suggesting that curlews did not take longer to recover after longer migration bouts.

Flight speed and flight height in relation to TWC

The flight speeds of both departing (GAM: $t=8.42, d f=32, p<0.001$ ) and arriving curlews (GAM: $t=5.07$, $d f=27, p<0.001$ ) were positively and highly significantly related to TWC (Fig. 5), suggesting that birds were able to increase their migration speeds with wind assistance. Interestingly, flight speeds during departure were significantly higher (mean: $73.8 \pm 18.5 \mathrm{~km} / \mathrm{h}$, range: $41.9-115.6 \mathrm{~km} / \mathrm{h}$ ) than speeds during arrival (mean: $55.3 \pm 11.9 \mathrm{~km} / \mathrm{h}$, range: $40.8-84.0 \mathrm{~km} / \mathrm{h}$ ), as indicated by the small overlap of confidence intervals in Fig. 5 (see also Table 1; Suppl. 1f). There was no difference in the TWC relationships between departing and arriving curlews (Table 1; Suppl. $1 \mathrm{~g}$ ).

Curlews departed at significantly higher altitudes during headwind compared with tailwind conditions (GAM: $t=-9.52, d f=19, p<0.001$ ), but there was no significant relationship between TWC and flight altitude in arriving curlews (Fig. 6 ; GAM: $t=-1.25, \mathrm{df}=13, \mathrm{p}=0.25$ ). As for flight speeds, flight altitudes were significantly higher and more variable during departure (mean: 1,113.3 $\pm 592.0 \mathrm{~m}$, range: 175.2$2337.7 \mathrm{~m}$ ) compared with during arrival (mean: $182.3 \pm 164.4 \mathrm{~m}$, range: 37.0-639.2 m) (Table 1; Suppl. $1 \mathrm{~h})$.

There was no significant relationship between TWC and the relative difference between the flown and linear distances, indicating that the straightness of the flight pass was not impacted by wind conditions. Finally, there was also no correlation between TWC and migration distance to the first stop or stop-over duration, suggesting that headwind conditions had no effect on flight distances and length of the first stop-over.

Departure/arrival decisions

The LASSO model showed that only one of the 73 predictors significantly influenced the departure day of curlews: curlews departed significantly later with increasing linear distance to their breeding sites (Fig. 7; GAM: $t=2.63, d f=37, p<0.05)$. Wind direction at the time of departure contrasted with the mean wind direction at the same time of day, and day of year 4 years prior to departure remained a predictor in the final LASSO model, but had no significant impact on departure day (GAM: $t=-0.77, d f=37, p=0.45$ ). Interestingly, LASSO did not select any other meteorological predictors, bird-related variables, or variables associated with the nearest stop-over event. Mean wind direction and wind force in the period from $90 \mathrm{~min}$ before to $90 \mathrm{~min}$ after departure were highly variable (Fig. 8a), which explains the absence of any significant relationships with day of departure.

According to LASSO, none of the 73 predictors was related to arrival day. As for departures, wind direction and force were highly variable (Fig. 8b). Wind force (but not wind direction) differed significantly between departure and arrival flights (Table 1; Suppl. 1i, j). During arrival, most of the higher wind forces were associated with north-easterly winds (Fig. 8b), which might have assisted some returning curlews, but 
eventually had no significant impact. This also led to a lack of any significant difference in tailwind conditions between departing and arriving curlews (Suppl. $1 \mathrm{~g}$ ).

In addition, there was no significant relationship between departure/arrival date and stop-over duration, indicating that curlews that migrated later did not have shorter stop-overs.

Repeatability:

Among the 42 curlews with departure information, we recorded multiple departures in subsequent years for 12 individual birds (2-5 consecutive years). It was therefore possible to assess the repeatability of the departure day in the same individuals in different years. The mean absolute difference in departure days in subsequent years was only $3.68 \pm 2.97$ days $(n=19)$. However, the variability in arrival days of returning curlews was more than twice as high $(7.17 \pm 4.83, n=12)$. The departure days recorded in each individual's first year were significantly related to the departure days in subsequent year(s) (Fig. 9; GAM: $t$ $=5.29, \mathrm{df}=18, \mathrm{p}<0.001)$, while there was no significant relationship for arrival dates $(\mathrm{GAM}: \mathrm{t}=-0.5, \mathrm{df}=$ $11, p=0.62)$.

There was also high site fidelity in terms of the locations of breeding and wintering sites, but less fidelity for the location of the nearest stop-over sites (Fig. 4). The repeatability of flight directions was also high, with a mean variability of only $9.7 \pm 8.2^{\circ}$ for departures and $13.3 \pm 10.2^{\circ}$ for arrivals among subsequent years for the same individuals.

\section{Discussion}

Wind and weather effects and flight heights

Our data confirmed that curlew flight speed increased with increasing TWC, in accordance with previous studies showing similar relationships $[6,20]$. Based on the clear benefit of faster flight speeds during tailwind conditions, we hypothesized that curlews would mainly select days with suitable tailwind conditions for their departure from (and arrival at) their wintering grounds in the Wadden Sea. This relationship was demonstrated in previous studies of songbirds [e.g. 12, 22], while long-distance migrating shorebirds were found to encounter unfavourable and potentially fatal wind conditions if they failed to time their departure precisely [10]. However, in contrast to our assumption, the current study revealed virtually no effect of wind or other weather parameters on the departure/arrival day for curlews, even when the actual weather during departure was compared with the mean weather conditions 4 days and/or 4 years prior to departure. Although curlews rarely departed during hours with precipitation (in accordance with other bird species) [12, 23-24], this predictor had no significant influence in our final model. The current findings were therefore not in agreement with previous studies, which found that the probability of departure of curlews from a pre-breeding staging site was reduced during precipitation [46]. In contrast, our findings were in accord with observations of departing curlews in China, where there was also no significant influence of wind force or wind direction [46]. The same holds true for the closely related whimbrel (Numenius phaeopus islandicus), for which there were no correlations with wind conditions for either direct flight or one-stop-over migration [47]. 
Although weather parameters had no impact on departure/arrival decisions, we found a significant negative correlation between TWC and flight altitude in curlews. Although there were no available data for wind speeds (and directions) of different air layers for this study, this pattern clearly suggests that curlews tried to find more favourable wind conditions at higher altitudes if they encountered headwinds at lower altitudes. In temperate latitudes, the prevailing westerly wind conditions in the higher air layers suggest wind assistance when ascending [48]. This behaviour has previously been recorded for nocturnal songbird migrants [25-26], as well as for diurnal long-distance migrants using radar techniques [49]. [50] found intensive songbird migration in air layers up to $3 \mathrm{~km}$ altitude in temperate regions, when the birds encountered headwind conditions close to the surface. The authors demonstrated that migrating birds benefited from the wind conditions in higher air layers by ascending, exclusively during their spring migration. This might explain why there was no significant relationship between flight altitude and TWC in arriving curlews during their autumn migration. The current results clearly suggest that curlews depart (and stay) at lower altitudes when wind conditions close to the surface are beneficial, and use higher air layers during spring migration when they encounter headwinds.

Interestingly, curlews arrived at significantly slower flight speeds and lower altitudes compared with departing curlews. Meteorological reasons for this can be excluded, given that the wind conditions and TWC were similar for departing and arriving individuals. One likely reason is that the linear distance to the nearest stop-over in arriving curlews was far smaller than for departing individuals, which might explain why departing curlews ascended to higher altitudes and had faster flight speeds compared with arriving birds.

In conclusion, the absence of clear relationships between departure decision and wind/weather parameters suggests that curlews behave conservatively and follow an individual time schedule driven by an internal genetic trigger $[14,51-52]$ (see discussion on repeatability below). If their individual departure day happens to coincide with headwind conditions, the birds seem to account for this by flying at higher altitudes. However, further studies are needed to determine if curlews have knowledge of the wind conditions at higher altitudes when they encounter headwinds on the ground.

Temporal patterns and location of breeding sites

According to our LASSO analysis, distance to the breeding site was the single (highly significant) predictor affecting the day of departure of curlews from the Wadden Sea. Counterintuitively and in contrast to our formulated hypothesis, birds with the longest migration distances showed the latest departure and arrival days. Given the long migration distance, we expected these curlews to leave earlier to allow them to complete their journey to their breeding grounds in time to start breeding. However, shorebirds have been shown to encounter higher food availability and have faster chick growth rates if they start nesting soon after snowmelt [53-54], suggesting that curlews should aim to arrive at their breeding sites as soon as the areas are free from snow and ice. This could in turn explain why curlews that breed further from their wintering grounds (e.g. in the eastern parts of Russia in this study) might wait longer to allow the snow and ice in their Arctic breeding grounds to melt, and/or to ensure that they 
encounter optimal arthropod densities. Similarly, [19] showed that colour-ringed curlews breeding in Fennoscandia departed later than birds breeding further west. Although this study dealt with a different sub-population, the results matched the patterns found in the current study.

We found that curlews wintering in the Wadden Sea departed within a very short time window (i.e. mostly between mid-April and mid-May). This contrasts with birds wintering in south-west Britain, which had already started to depart during February and March [19]. However, in contrast to British curlews that breed in north-western Europe [19], all but one of the curlews reported in the present study bred in Russia, i.e. much further east. The more condensed departure window in our study might thus also be a consequence of the relatively late availability of breeding sites due to snow and ice melt. This emphasises the need for the birds to have an internal clock to ensure their timely departure.

The main window of arrival of birds in the Wadden Sea was late June to mid-July, which is about 2 weeks later than reported for birds breeding in central or northern Europe [19]. Although desertion of offspring by females is common in shorebirds and has been shown for curlews [27], we found no sex differences in departure patterns, and only a non-significant tendency for females to arrive earlier. The reason for this is unclear. It is possible that some birds failed to rear chicks successfully, leading to the earlier arrival of at least some males.

Departures of songbirds usually occur at night and around sunset $[22,51]$ and the same is true for many long-distance migratory wader species, given that birds are thought to take advantage of favourable atmospheric factors during the night and to calibrate their orientation systems before they start in the evening hours [55-56]. Our results support these patterns, with more curlews departing during the early evening or early nighttime. However, an earlier study of curlews departing from a final pre-breeding stopover site in China showed high variability in terms of the time of day for departures [46]. The reason for these different findings remains unclear. Given the higher number of individuals arriving during morning and afternoon, our results suggest the existence of a strong temporal trigger regulating departure decisions, but a weaker such trigger for arrivals.

Correlations with first and last stop-overs

We expected that the departure day and TWC would be significantly related to the distance to the nearest stop-over site and the stop-over duration; however, no such correlation was found. Curlews did not stage for shorter periods if they departed later, nor did they stage for longer if they encountered headwind conditions during the first part of their migration to allow more time for re-fuelling. This finding is in accordance with studies of songbirds, which likewise showed no or only weak relationships [57-58]. Similar results were also found for whimbrels, with no impact of wind conditions on stop-over patterns; however, in contrast to our study, they tended to skip a potential stop-over when they departed later [47].

Repeatability 
In a recent review, [52] presented evidence for genetic control of the timing of bird migration. However, the authors also found much individual variation in this genetic programme as a result of interactions with environmental and social factors, as well as due to individual learning. The curlews in the current study also demonstrated a clear genetic circannual rhythm, given that individual curlews showed very little variation in departure and arrival patterns among subsequent years, and did not time their departure according to the weather. The current results thus provide a robust example of the concept of an internal clock, responsible for timing bird migration $[14,51]$. In contrast to these results however, black-tailed godwits (Limosa limosa limosa) tracked across subsequent years exhibited a much broader window of inter- and intraspecific timing of migration [59]. The authors suggest that this broad window of repeatability indicated weak selective forces with respect to migration timing. This assumption would suggest that such forces are strong for curlews, although for the specific mechanisms affecting the high inter- and intraspecific repeatability of migration timing evidence is currently lacking. In contrast, [8] hypothesized a conservative annual-cycle strategy in long-distance migrants that was thought to minimise risks and reduce carry-over effects. Our study may support this hypothesis, given that curlews clearly showed constant, conservative patterns in terms of their departure decisions, independent of the weather conditions at their wintering sites. These findings are in line with other Arctic breeding birds, such as bar-tailed godwits (Limosa limosa baueri) from New Zealand, which also showed high repeatability [60].

\section{Conclusions}

The results of the current study demonstrated constant temporal departure and arrival patterns in curlews, with no significant impact of meteorological conditions. The high repeatability of the departure day in the same individuals in subsequent years suggests a genetic trigger regulating the timing of migration. These results clearly show that curlews departed during any weather conditions, including headwinds, which seemed to be accounted for by flying at higher altitudes. However, the main factor driving the timing of migration seems to be the date, suggesting the existence of an internal clock prompting the start of migration. Follow-up studies are needed to explore the timing of migration in immature curlews, ideally by tagging birds from the same clutch and their parents. Further insights into the timing of migration in closely related birds might help us to understand the genetic mechanisms triggering temporal migration patterns.

\section{Abbreviations}

GPS

Global Positioning System

GSM

Global System for Mobile Communications

TWC

tailwind component 


\section{Declarations}

\section{Ethics approval and consent to participate}

Permission to attach GPS tags was issued by the Ministerium für Energiewende, Landwirschaft, Umwelt, Natur und Digitalisierung of the federal state of Schleswig-Holstein (file numbers V 312-7224.121-37(423/13) and V 241-35852/2017(88-7/17)) as well as by the Niedersächsisches Landesamt für Verbraucherschutz und Lebensmittelsicherheit of the federal state of Lower Saxony (file number 33-1942502-04-17/2699). Catching and treatment of birds complied with current EU and German laws. All authors consent to participate in this study.

\section{Consent for publication}

Not applicable.

Availability of data and materials

The tracking data of curlews are available in www.movebank.org.

Competing interests

The authors declare that they have no competing interests.

\section{Funding}

Parts of this study were conducted within the project "StopP-Synthese - from Sediment to Top Predators" (FKZ 03F672B) funded under the FONA programme of the German Federal Ministry of Research and Education (BMBF), and by the projects "Birdmove" (FKZ 3515822100) and "Trackbird" (FKZ 3519861400) funded by the Federal Agency for Nature Conservation.

\section{Author's contributions}

PS designed the study, conducted the fieldwork, performed the data analyses and wrote most parts of the manuscript. MM designed and performed the statistical tests and wrote parts of the method section. KHV recorded and analysed the meteorological data. PB wrote parts of the manuscript. SG designed the study and compiled the movement data. All authors read and approved the final manuscript.

\section{Acknowledgements}

The National Park Administration within the Landesbetrieb für Küstenschutz, Nationalpark und Meeresschutz, provided permission to enter bird protection sites for catching. We thank our colleagues for assistance in nocturnal bird catching and in particular Gerhard (Niko) Nikolaus and members from the Schutzstation Wattenmeer e.V. We thank S. Furness for providing linguistic support. 


\section{References}

1. Schaefer JA, Mahoney SP. Spatial dynamics of the rise and fall of caribou (Rangifer tarandus) in Newfoundland. Can J Zool. 2013;91:767-74.

2. Briedis $M$, Krist $M$, Král $M$, Voigt $C$, Adamík P. Linking events throughout the annual cycle in a migratory bird - non-breeding period buffers accumulation of carry-over effects. Behav Ecol Sociobiol. 2018;72:93. https://doi.org/10.1007/s00265-018-2509-3.

3. Pelletier D, Seyer Y, Garthe S, Bonnefoi S, Philips A, Guillemette M. So far, so good... Similar fitness consequences and overall energetic costs for short and long-distance migrants in a seabird. PLoS One. 2019;15(3):e0230262. https://doi.org/10.1371/journal.pone.0230262.

4. Sawyer $\mathrm{H}$, LeBeau CW, McDonald T, Xu W, Middleton AD. All routes are not created equal: An ungulate 's choice of migration route can influence its survival. J Appl Ecol. 2019;56:1860-9. https://doi.org/10.1111/1365-2664.13445.

5. Sergio F, Tavecchia G, Tanferna A, Blas J, Blanco G, Hiraldo F. When and where mortality occurs throughout the annual cycle changes with age in a migratory bird: individual vs. population implications. Sci Rep. 2019;9:17352. https://doi.org/10.1038/s41598-019-54026-z.

6. Alerstam T. Bird migration speed. In: Berthold P, Gwinner E, Sonnenschein E, editors. Avian migration. Springer; 2003. p. 253-67.

7. Gill RE Jr, Tibbits TL, Douglas DC, Handel CM, Mulcahy DM, Gottschalck JC, et al. Extreme endurance flights by landbirds crossing the Pacific Ocean: ecological corridor rather than barrier? Proc R Soc B. 2009;276:447-57. doi:10.1098/rspb.2008.1142.

8. Conklin JR, Senner NR, Battley PF, Piersma T. Extreme migration and the individual quality spectrum. J Avian Biol. 2017;48:19-36. doi:10.1111/jav.01316.

9. Franke A, Therrien J-F, Descamps S, Bêty J. Climatic conditions during outward migration affect apparent survival of an arctic top predator, the peregrine falcon Falco peregrinus. J Avian Biol. 2011;42:544-51. doi:10.1111/j.1600-048X.2011.05466.x.

10. Alves JA, Dias MP, Méndez V, Katrínardóttir B, Gunnarsson TG. Very rapid long-distance sea crossing by a migratory bird. Sci Rep. 2016;6:38154. doi:10.1038/srep38154.

11. Haest $B$, Hüppop $O$, Bairlein $F$. The influence of weather on avian spring migration phenology: What, where and when? Glob Chang Biol. 2018;1-20. doi:10.1111/gcb.14450.

12. Brust V, Michalilk B, Hüppop O. To cross or not to cross - thrushes at the German North Sea coast adapt flight and routing to wind conditions in autumn. Mov Ecol. 2019;7:32. https://doi.org/10.1186/s40462-019-0173-5B.

13. Fayet AL, Freeman R, Shoji A, Kirk HL, Padget O, Perrins CM, et al. Carry-over effects on the annual cycle of a migratory seabird: an experimental study. J Animal Ecol. 2016;85:1516-27. doi:10.1111/1365-2656.12580.

14. Åkesson S, llieva M, Karagicheva J, Rakhimberdiev E, Tomotani B, Helm B. Timing avian longdistance migration: from internal clock mechanisms to global flights. Philos Trans R Soc B. 
2017;372:20160252. doi.org/10.1098/rstb.2016.0252.

15. BirdLife International. Species factsheet: Numenius arquata. 2020. http://www.birdlife.org. Accessed September 2020.

16. Kleefstra R, Hormann M, Bregnballe T, Frikke J, Günther K, Hälterlein B, et al. Trends of migratory and wintering waterbirds in the Wadden Sea 1987/1988-2016/2017. Wadden Sea Ecosystem No. 39. Common Wadden Sea Secretariat, Joint Monitoring Group of Migratory Birds in the Wadden Sea, Wilhelmshaven, Germany. 2019. https://www.waddensea-

worldheritage.org/sites/default/files/2019_Ecosystem39_Trends\%20of\%20Waterbirds.pdf. Accessed September 2020.

17. Blew J, Günther K, Hälterlein B, Kleefstra R, Laursen K, Scheiffarth G. Trends of migratory and wintering waterbirds in the Wadden Sea 1987/1988-2011/2012. Wadden Sea Ecosystem No. 34. Common Wadden Sea Secretariat, Joint Monitoring Group of Migratory Birds in the Wadden Sea, Wilhelmshaven, Germany. 2015. https://www.waddensea-worldheritage.org/de/node/447. Accessed September 2020.

18. Schwemmer P, Enners L, Garthe S. Migration routes of Eurasian Curlews (Numenius arquata) resting in the eastern Wadden Sea based on GPS telemetry. J Ornithol. 2016;157:901-05.

19. Sanders JD, Rees EC. Arrival and departure patterns of Eurasian Curlew Numenius a. arquata wintering on the River Severn estuary, Gloucestershire, southwest England. Wildfowl. 2018;68:15571.

20. Garthe S, Montevecchi WA. Davoren GK Flight destinations and foraging behavior of northern gannets (Sula bassana) preying on a small forage fish in a low-Arctic ecosystem. Deep Sea Res Part II. 2007;54:311-20.

21. Chevallier D, Handrich Y, Georges J-Y, Baillon F, Brossault P, Aurouet A, Le Maho Y, Massemin S. Influence of weather conditions on the flight of migrating black storks. Proc R Soc B. 2010;277:2755-64. doi:10.1098/rspb.2010.0422.

22. Eikenaar C, Schmaljohann H. Wind conditions experienced during the day predict nocturnal restlessness in a migratory songbird. Ibis. 2015;157:125-32.

23. Schmaljohann H, Lisovski S, Bairlein F. Flexible reaction norms to environmental variables along the migration route and the significance of stopover duration for tota pseed of migration in a songbird migrant. Front Zool. 2017;14:17. doi:10.1186/s12983-017-0203-3.

24. Summers RW, de Raad AL, Bates B, Etheridge B, Elkins N. Non-breeding areas and timing of migration in relation to weather of Scottish-breeding common sandpipers Actitis hypoleucos. J Avian Biol. 2019; e01877. doi:10.1111/jav.01877.

25. Bruderer B. Nocturnal bird migration in the Negev (Israel) - a tracking radar study. Ostrich. 1993;65:204-12. https://doi.org/10.1080/00306525.1994.9639683.

26. Kemp MU, Shamoun-Baranes J, Dokter AM, van Loon E, Bouten W. The influence of weather on the flight altitude of nocturnal migrants in mid-latitudes. Ibis. 2013;155:734-49. 
27. Currie D, Valkama J, Berg $\AA$, Boschert $M$, Norrdahl K, Hänninen M, et al. Sex roles, parental effort and offspring desertion in the monogamous Eurasian Curlew Numenius arquata. Ibis. 2001;143:642-50.

28. Ma Z, Hua N, Zhang X, Guo H, Zhao B, Ma Q, et al. Wind conditions affect stopover decisions and fuel stores of shorebirds migrating through the south Yellow Sea. Ibis. 2011;153:755-67.

29. Guillaumet A, Dorr B, Wang G, Taylor JD, Chipman RB, Scherr H, et al. Determinants of local and migratory movements of Great Lakes double-crested cormorants. Behav Ecol. 2011;22:1096-103.

30. Phillips RA, Xavier JC, Croxall JP. Effects of satellite transmitters on albatrosses and petrels. Auk. 2003;120:1082-90.

31. Environmental Systems Research Institute (ESRI). ArcGIS v.10.3. ESRI, Redlands, California; 2011.

32. Lund U, Agostinelle C, Arai H, Gagliardi A, Portugues EG, Giunchi D, et al. Package 'circular'. https://cran.r-project.org/web/packages/circular/circular.pdf. 2017. Accessed September 2020.

33. Carslaw D, Ropkins K. Package 'openair'. 2020. https://cran.rproject.org/web/packages/openair/openair.pdf. Accessed September 2020.

34. Alerstam T, Hedenström A, Åkesson S. Long-distance migration: evolution and determinants. Oikos. 2003;103:247-60.

35. Fransson T. Patterns of migratory fuelling in whitethroats Sy/via communis in relation to departure. J Avian Biol. 1998;29:569-73.

36. R Core Team. R: a language and environment for statistical computing. R Foundation for Statistical Computing, Vienna, Austria. 2017. https://www.R-project.org/. Accessed September 2020.

37. Wickham H, Chang W, Henry L, Pedersen TL, Takahashi K, Wilke C, et al. R package 'ggplot2'. 2010. https://cran.r-project.org/web/packages/ggplot2/ggplot2.pdf. Accessed September 2020.

38. Zuur AF. A Beginner's Guide to Generalized Additive Models with R. Newburgh:Highland Statistics Ltd; 2012.

39. Wood S. Generalized Additive Models: an Introduction with R. 2nd ed. London: Chapman and Hall; 2017.

40. Wood S. Package 'mgcv'. 2020. https://cran.r-project.org/web/packages/mgcv/mgcv.pdf. Accessed September 2020.

41. Akaike H. Information theory and an extension of the maximum likelihood principle. In: Petrov BN, Caski F, editors. Proceeding of the Second International Symposium on Information Theory. Budapest: Akademiai Kiado; 1973. p. 267-81.

42. Tibshirani R. Regression shrinkage and selection via the lasso. J R Stat Soc Series B Stat Methodol. 1996;58:267-88.

43. Tibshirani R. The lasso method for variable selection in the Cox model. Stat Med. 1997;16:385-95.

44. Usai M, Goddard M, Hayes B. LASSO with cross-validation for genomic selection. Genet Res (Camb). 2009;91:427-36.

45. Korner-Nievergelt F, Roth $T$, von Felten S, Guelat J, Almasi B, Korner-Nievergelt P. Bayesian data analysis in ecology using linear models with R, BUGS, and Stan. London: Elsevier; 2015. 
46. Tan K, Chohi C-Y, Peng H, Melville DS, Ma Z. Migration departure strategies of shorebirds at a final pre-breeding stopover site. Avian Res. 2018;9:15. https://doi.org/10.1186/s40657-018-0108-7.

47. Carneiro C, Gunnarsson TG, Alves JA. Linking weather and phenology to stopover dynamics of a long-distance migrant. Front Ecol Evol. 2020;8:145. doi:10.3389/fevo.2020.00145.

48. Watts A. Instant Weather Forecasting: You Can Predict the Weather. Adlard Coles Ltd. 1975.

49. Mateos-Rodríguez M, Liechti F. How do diurnal long-distance migrants select flight altitude in relation to wind? Behav Ecol. 2012;23:403-40. doi:10.1093/beheco/arr204.

50. Dokter AM, Shamoun-Baranes J, Kemp MU, Tijm S, Holleman I. High altitude bird migration at temperate latitudes: a synoptic perspective on wind assistance. PLoS One. 2013;8:e52300. doi:10.1371/journal.pone.0052300.

51. Müller F, Taylor PD, Sjöberg S, Muheim R, Tsvey A, Mackenzie SA, et al. Towards a conceptual framework for explaining variation in nocturnal departure time of songbird migrants. Mov Ecol. 2016;4:24. doi:10.1186/s40462-016-0089-2.

52. Åkesson S, Helm B. Endogenous programs and flexibility in bird migration. Front Ecol Evol. 2020;8:78. doi:10.3389/fevo.2020.00078.

53. Reenerkens J, Schmidt NM, Gilg O, Hansen J, Hansen LH, Moreau J, et al. Effects of food abundance and early clutch predation on reproductive timing in a high Arctic shorebird exposed to advancements in arthropod abundance. Ecol Evol. 2016;6:7375-86. doi:10.1002/ece3.2361.

54. Saalfeld ST, McEwen DC, Kesler DC, Butler MG, Cunningham JA, Doll AC, et al. Phenological mismatch in Arctic-breeding shorebirds: Impact of snowmelt and unpredictable weather conditions on food availability and chick growth. Ecol Evol. 2019;9:6693-707. doi:10.1002/ece3.5248.

55. Piersma T, Zwarts L, Bruggemann JH. Behavioural aspects of the departure of waders before longdistance flights: flocking, vocalization, flight paths and diurnal timing. Ardea. 1990;78:157-84.

56. Åkesson S, Hedenström A. How migrants get there: Migratory performance and orientation. Bioscience. 2007;57:123-33.

57. Bulyuk VN, Tsvey A. Regulation of stopover duration in the European Robin Erithacus rubecula. J Ornithol. 2013;154:1115-26. doi:10.1007/s10336-013-0981-0.

58. Hays QR, Morbey YE, Hobson KA, Jyons JE, Guglielmo CG. Effects of migration distance and sex on stopover timing and refueling by Wilson's Warblers. J Field Ornithol. 2018;89:149-64. doi:10.1111/jofo.12246.

59. Verhoeven MA, Loonstra AHJ, Senner NR, McBride AD, Both C, Piersma T. Variation from an unknown source: large inter-individual differences in migrating black-tailed godwits. Front Ecol Evol. 2019;7:31. doi:10.3389/fevo.2019.00031.

60. Battley PF. Consistent annual schedules in a migratory shorebird. Biol Lett. 2006;2:517-20. doi:10.1098/rsbl.2006.0535.

\section{Figures}



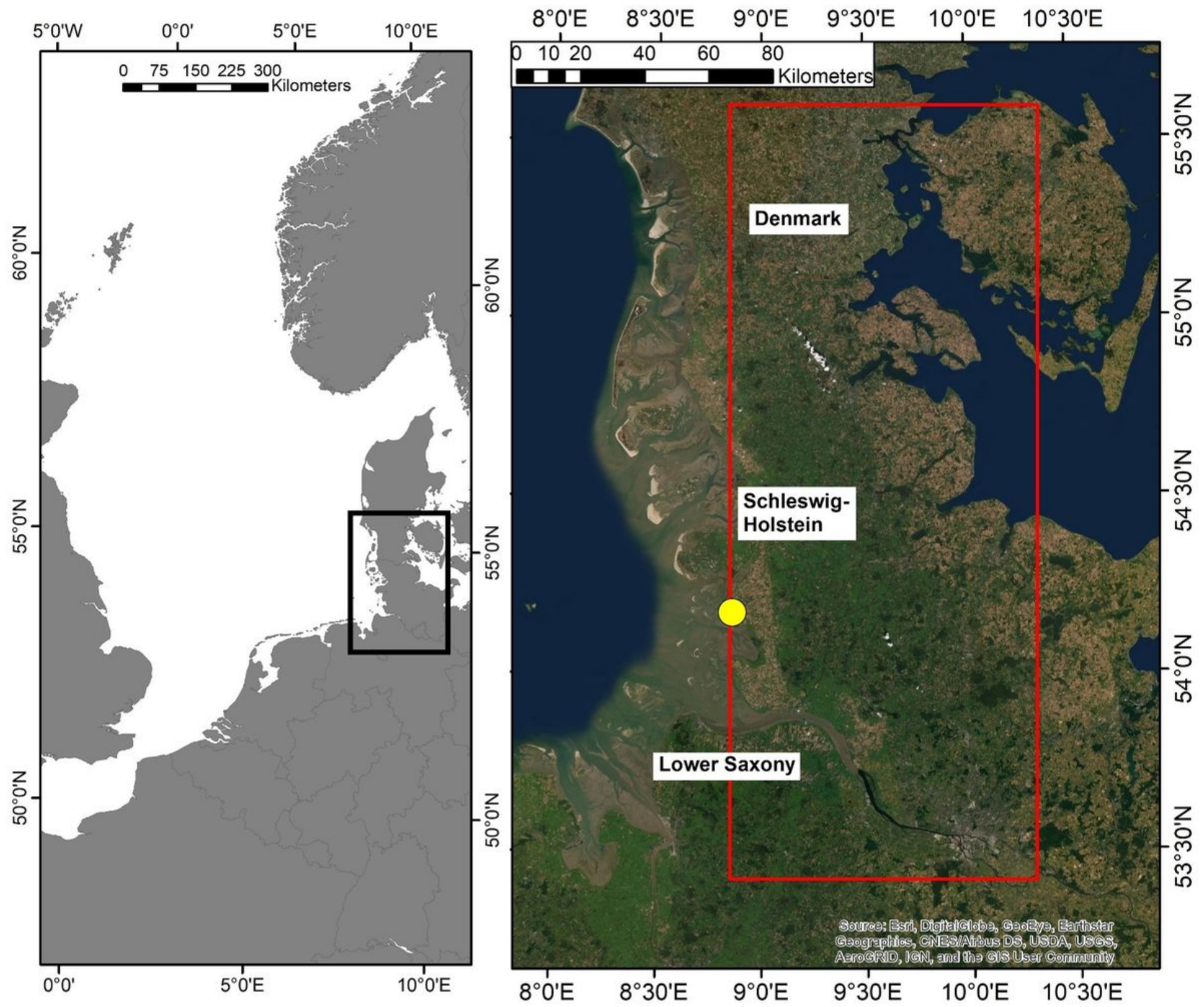

\section{Figure 1}

Left: location of study area in the southern part of the German Wadden Sea, south-eastern North Sea coast, indicated by black box. Right: study area for analyses of tailwind component flight speeds and flight altitudes (red box) and location of weather recording station (yellow dot). Satellite image: ESRI, DigitalGlobe, GeoEye, Earthstar Geographics, CNES/Airbus DS, USDA, USGS, AeroGRID, IGN, and the GIS User Community. Note: The designations employed and the presentation of the material on this map do not imply the expression of any opinion whatsoever on the part of Research Square concerning the legal status of any country, territory, city or area or of its authorities, or concerning the delimitation of its frontiers or boundaries. This map has been provided by the authors. 

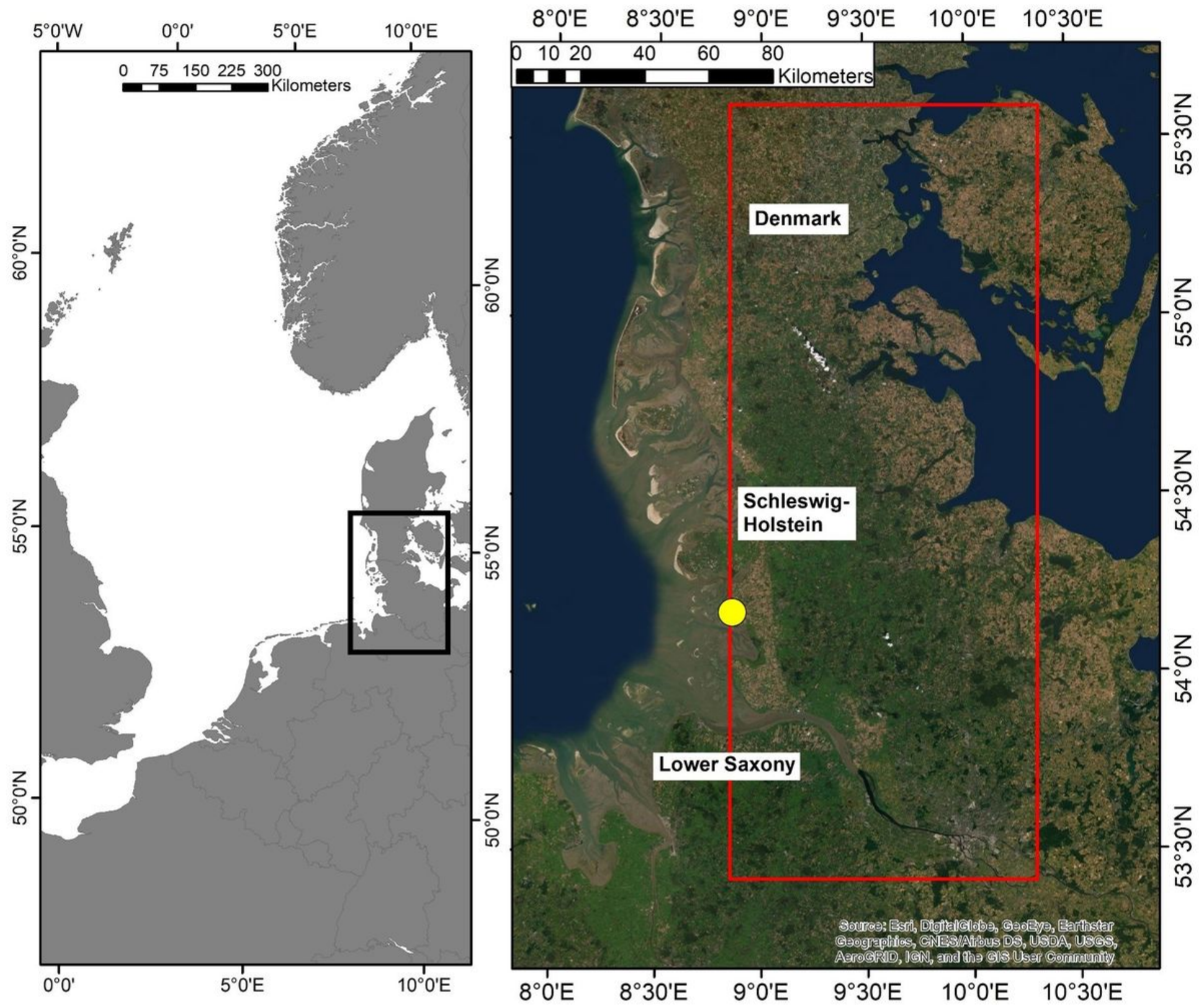

\section{Figure 1}

Left: location of study area in the southern part of the German Wadden Sea, south-eastern North Sea coast, indicated by black box. Right: study area for analyses of tailwind component flight speeds and flight altitudes (red box) and location of weather recording station (yellow dot). Satellite image: ESRI, DigitalGlobe, GeoEye, Earthstar Geographics, CNES/Airbus DS, USDA, USGS, AeroGRID, IGN, and the GIS User Community. Note: The designations employed and the presentation of the material on this map do not imply the expression of any opinion whatsoever on the part of Research Square concerning the legal status of any country, territory, city or area or of its authorities, or concerning the delimitation of its frontiers or boundaries. This map has been provided by the authors. 


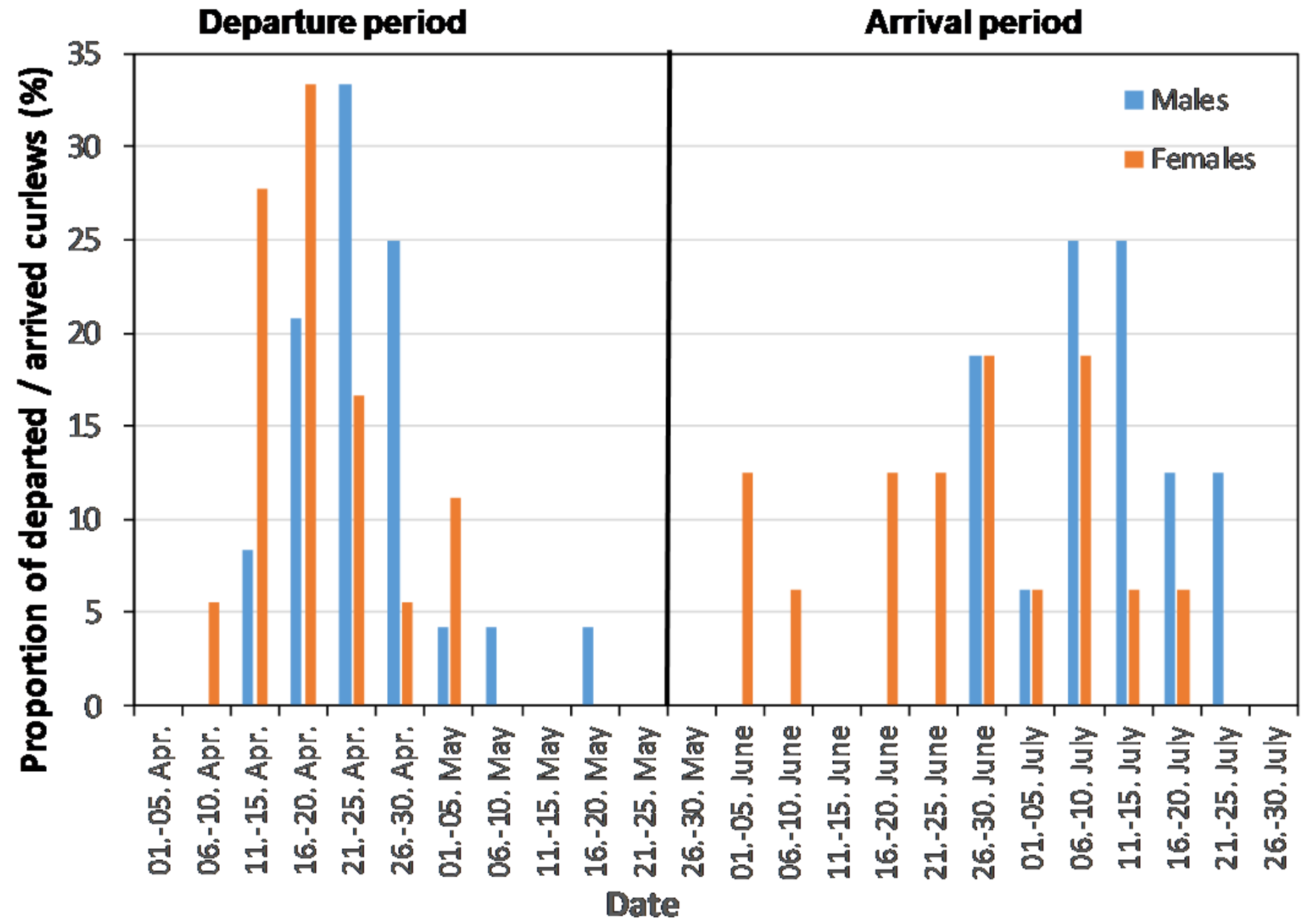

Figure 2

Proportion of curlews that departed from (left) and arrived at the wintering site (right) in relation to date. 


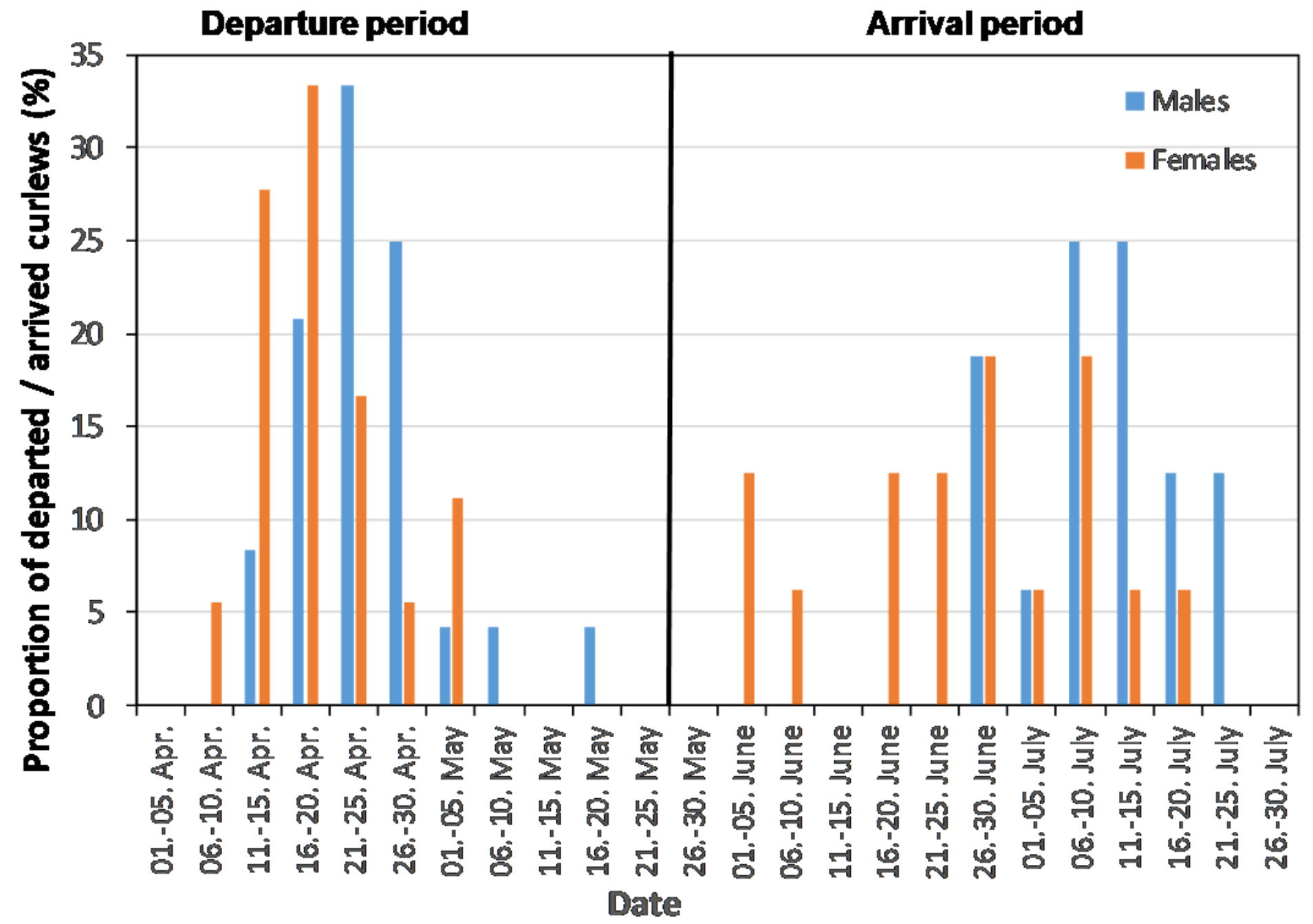

Figure 2

Proportion of curlews that departed from (left) and arrived at the wintering site (right) in relation to date.
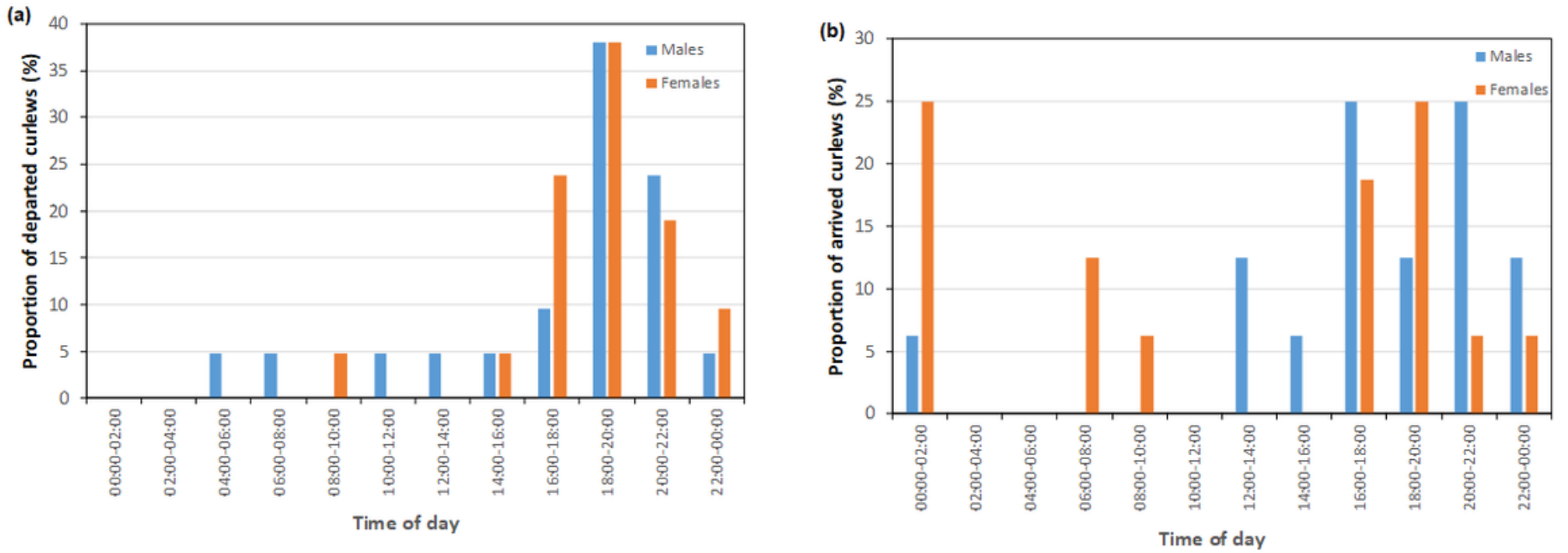

Figure 3 
Proportion of curlews that departed from (a) and arrived at the wintering site (b) in relation to time of day (UTC).
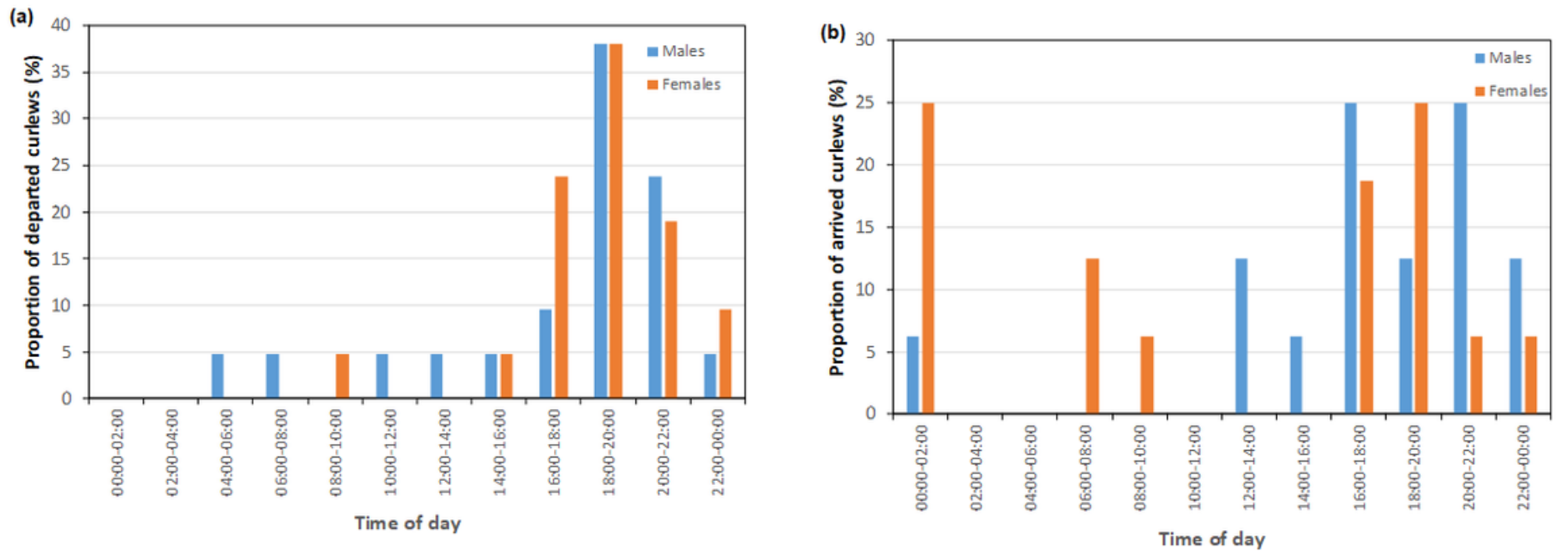

Figure 3

Proportion of curlews that departed from (a) and arrived at the wintering site (b) in relation to time of day (UTC). 


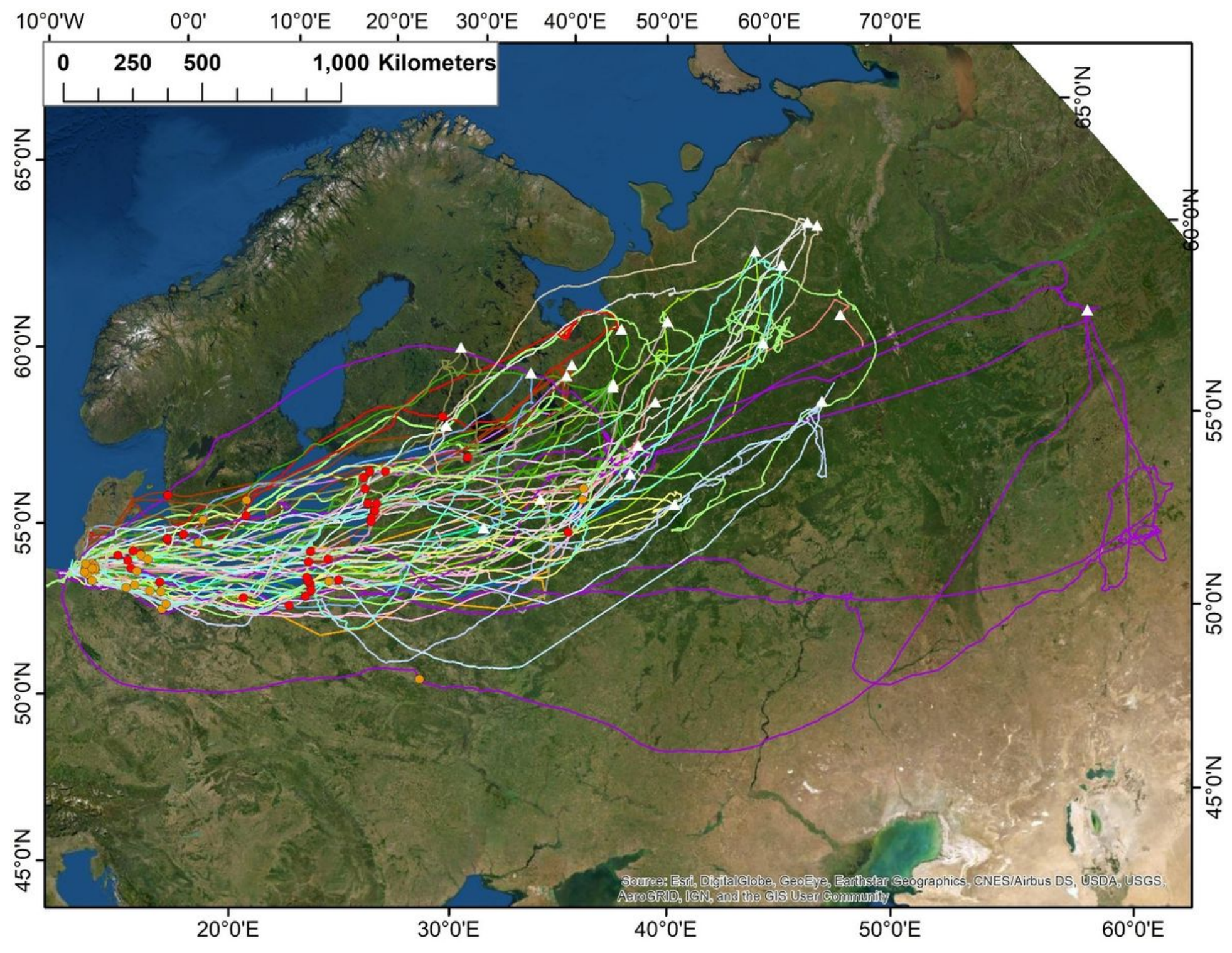

Figure 4

Flight tracks ( $n=41)$ of 23 curlews between their wintering sites in the Wadden Sea and their breeding sites (white triangles). Red and orange dots indicate location of the first and last stop-over sites, respectively. Satellite image: see Fig. 1. Note: The designations employed and the presentation of the material on this map do not imply the expression of any opinion whatsoever on the part of Research Square concerning the legal status of any country, territory, city or area or of its authorities, or concerning the delimitation of its frontiers or boundaries. This map has been provided by the authors. 


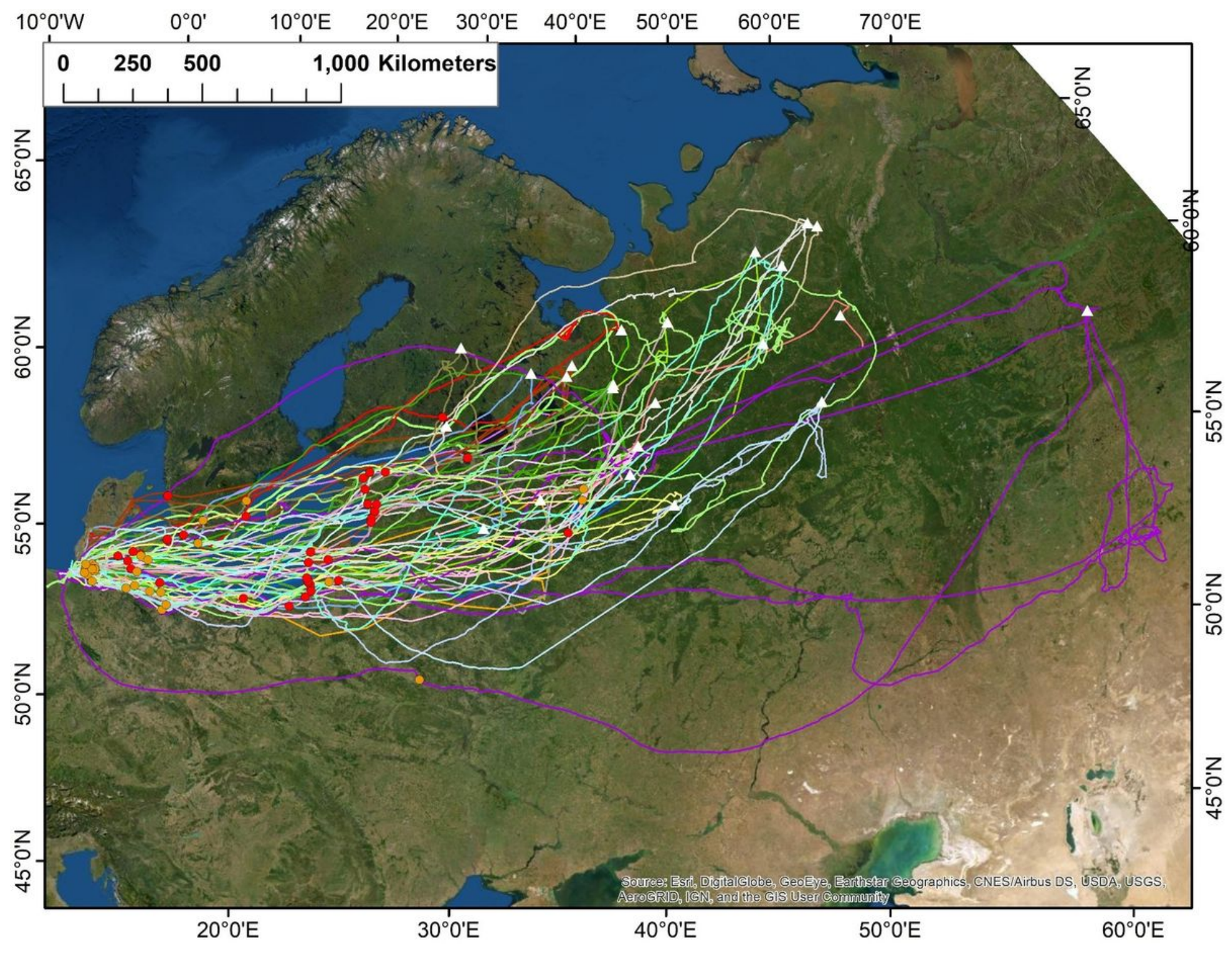

Figure 4

Flight tracks $(n=41)$ of 23 curlews between their wintering sites in the Wadden Sea and their breeding sites (white triangles). Red and orange dots indicate location of the first and last stop-over sites, respectively. Satellite image: see Fig. 1. Note: The designations employed and the presentation of the material on this map do not imply the expression of any opinion whatsoever on the part of Research Square concerning the legal status of any country, territory, city or area or of its authorities, or concerning the delimitation of its frontiers or boundaries. This map has been provided by the authors. 


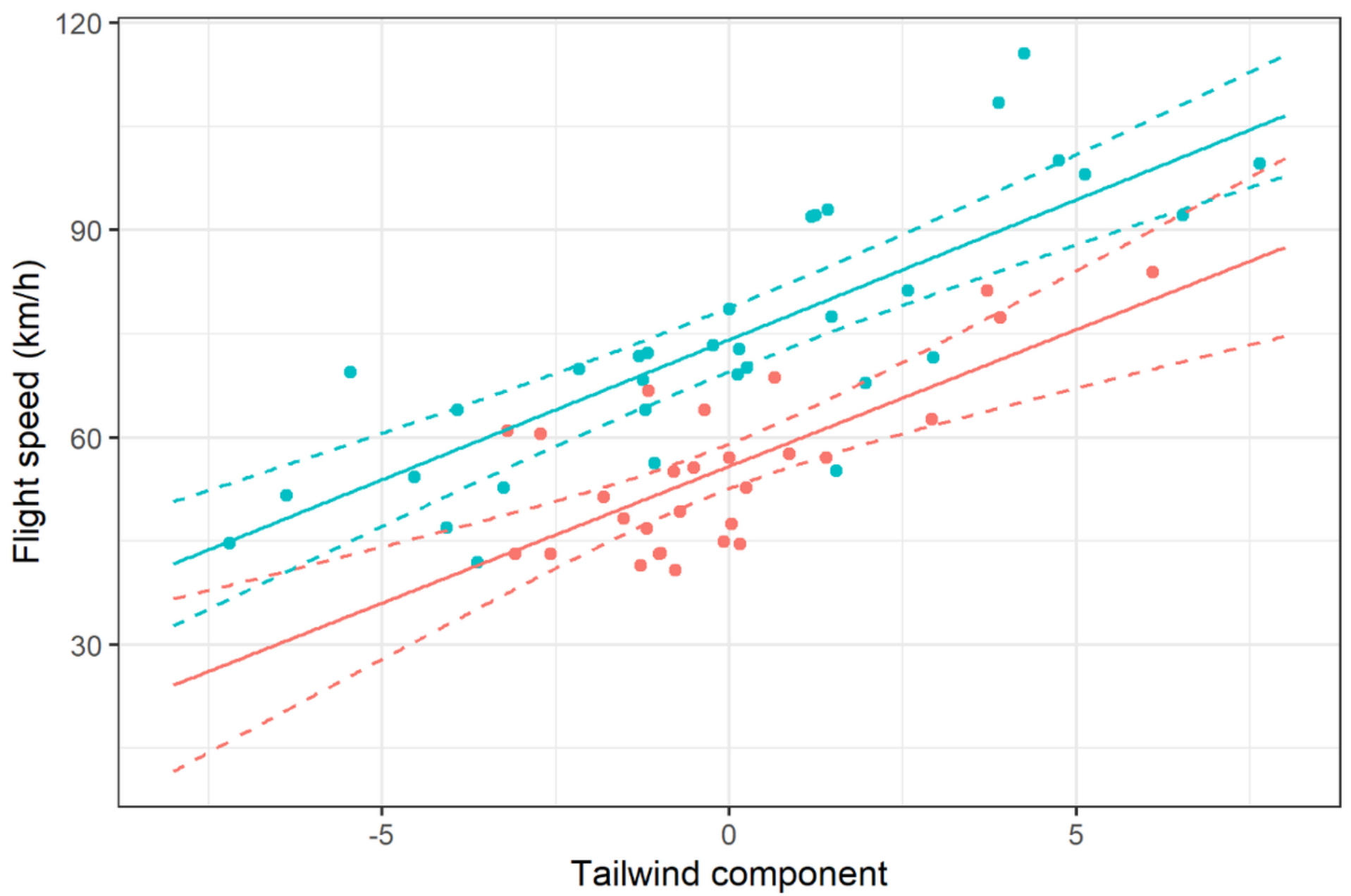

Figure 5

Flight speed of departing (blue) and arriving curlews (red) in relation to tailwind component. Solid line: model curve; dashed lines: $95 \%$ confidence intervals. 


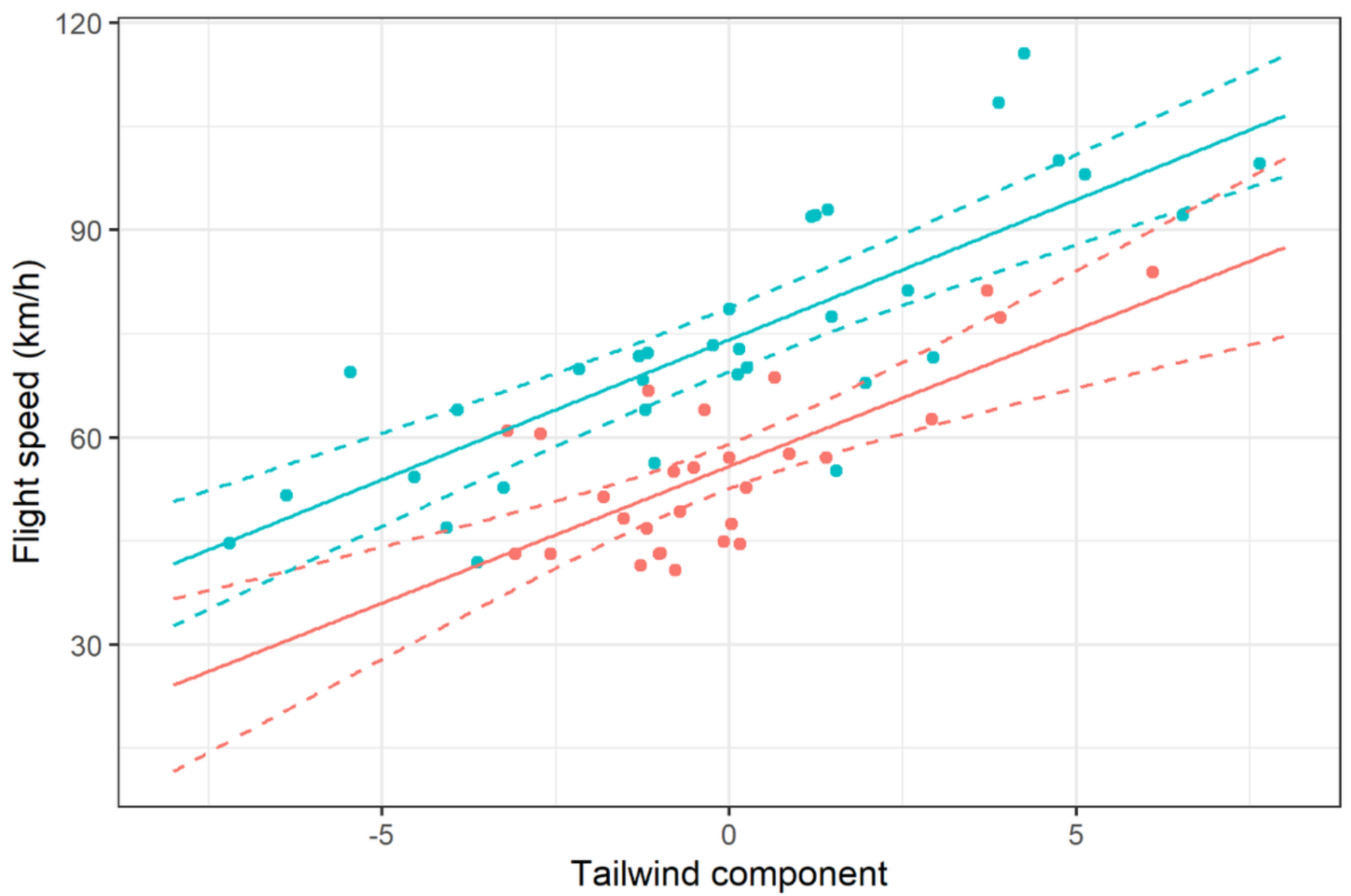

Figure 5

Flight speed of departing (blue) and arriving curlews (red) in relation to tailwind component. Solid line: model curve; dashed lines: $95 \%$ confidence intervals. 


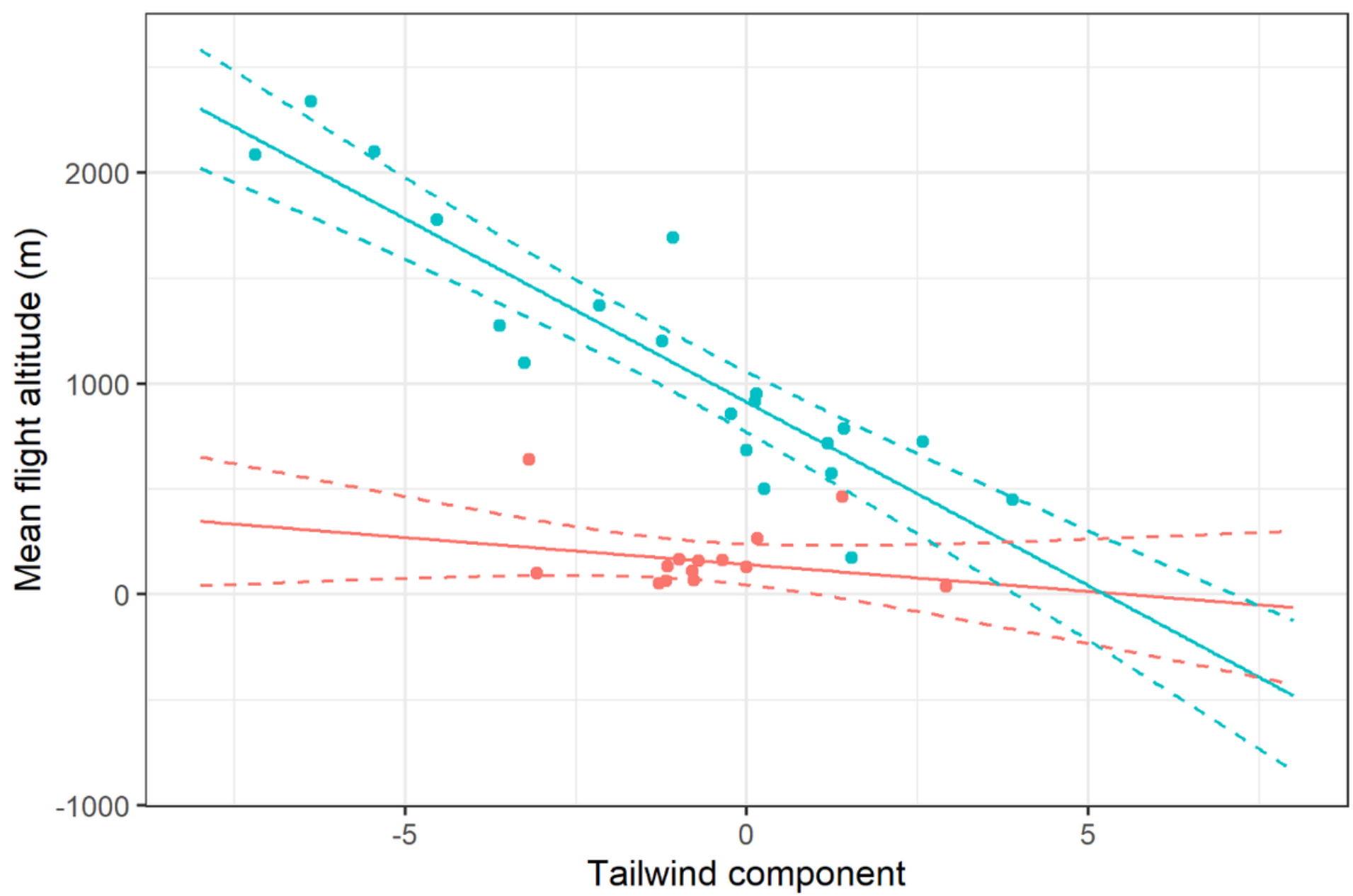

Figure 6

Flight altitudes of departing (blue) and arriving curlews (red) in relation to tailwind component. Solid line: model curve; dashed lines: $95 \%$ confidence intervals. 


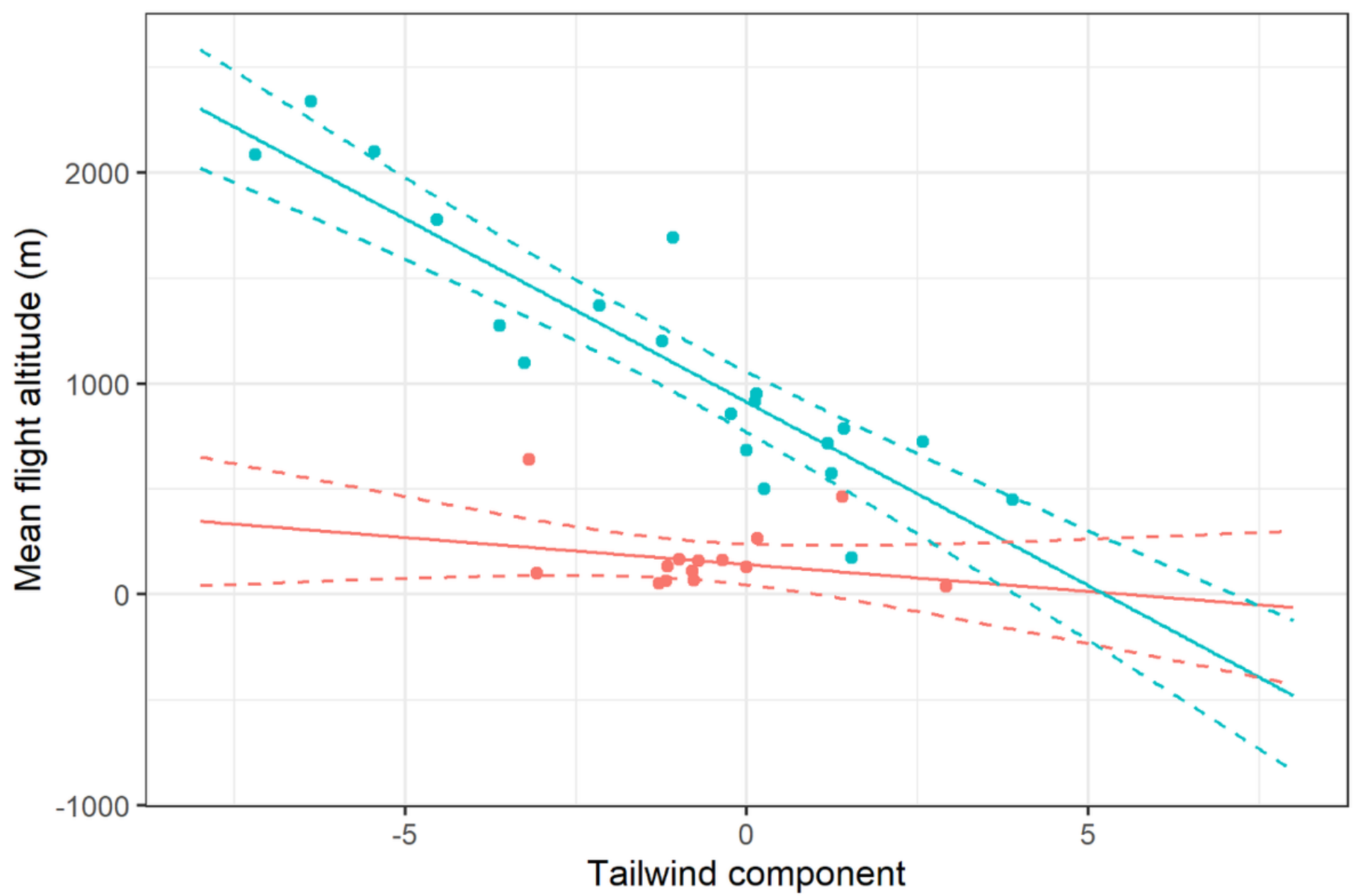

Figure 6

Flight altitudes of departing (blue) and arriving curlews (red) in relation to tailwind component. Solid line: model curve; dashed lines: $95 \%$ confidence intervals. 


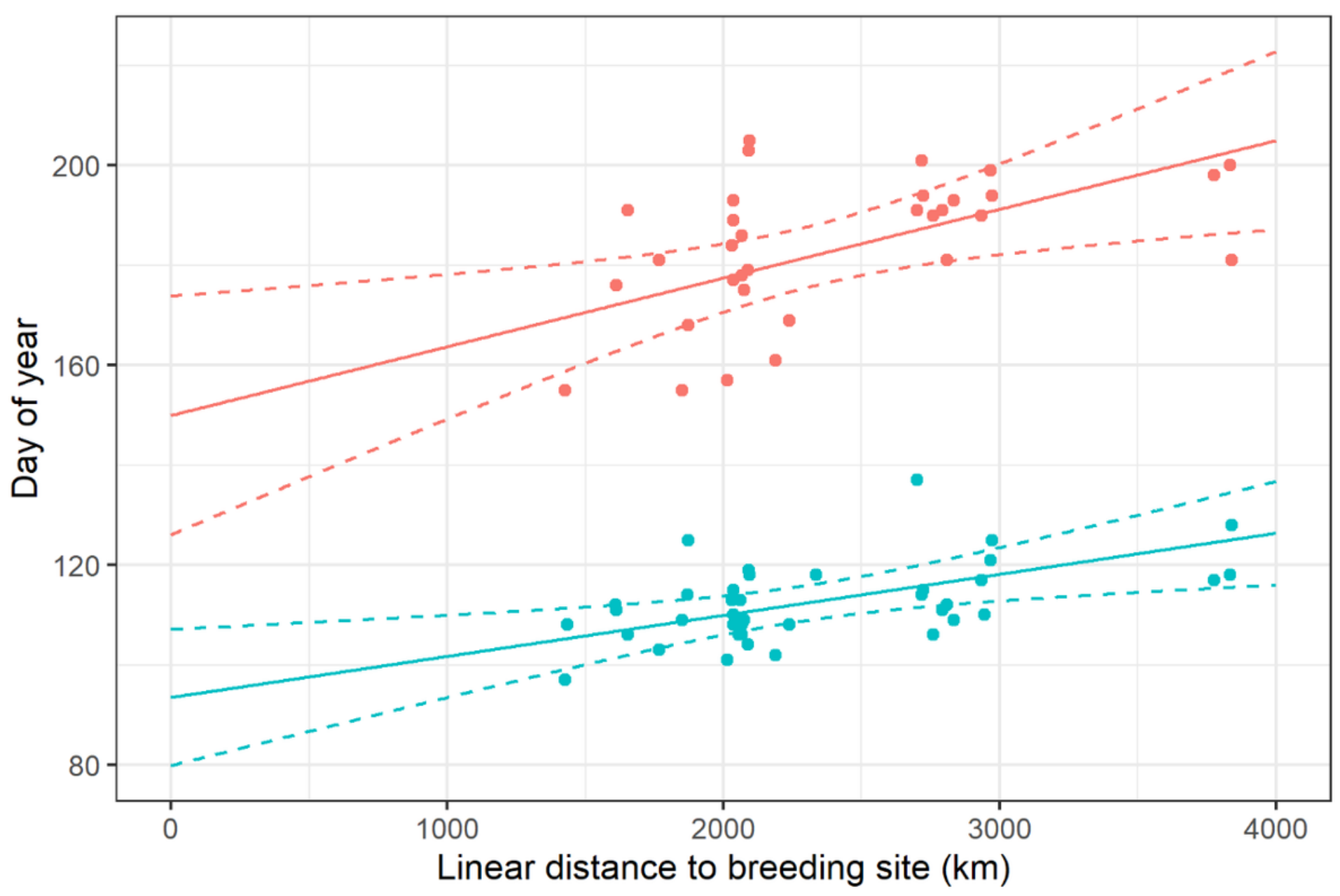

Figure 7

Day of year of departure (blue) and arrival (red) in relation to linear distance to the breeding site. Solid line: model curve; dashed lines: $95 \%$ confidence intervals. 


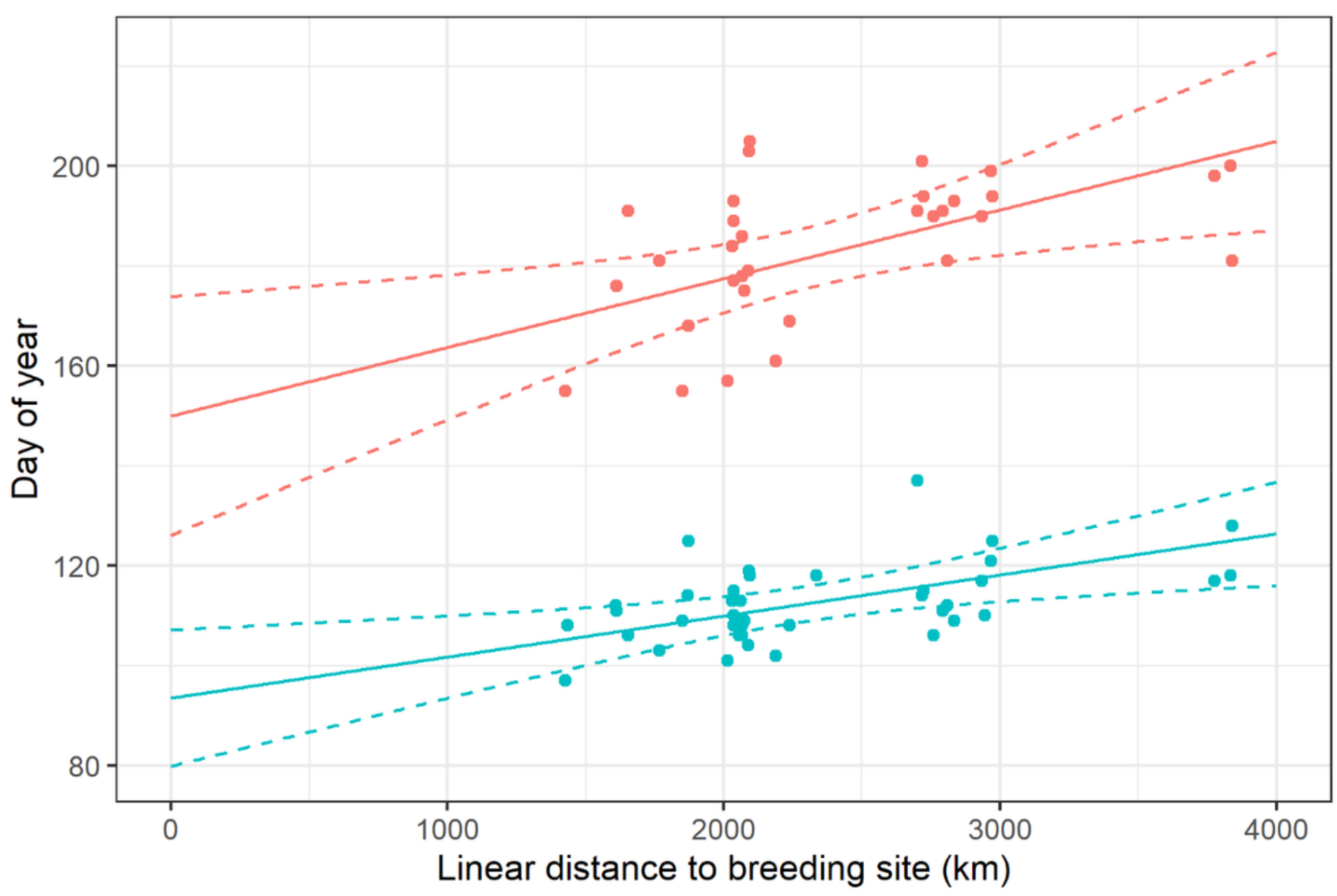

Figure 7

Day of year of departure (blue) and arrival (red) in relation to linear distance to the breeding site. Solid line: model curve; dashed lines: 95\% confidence intervals.
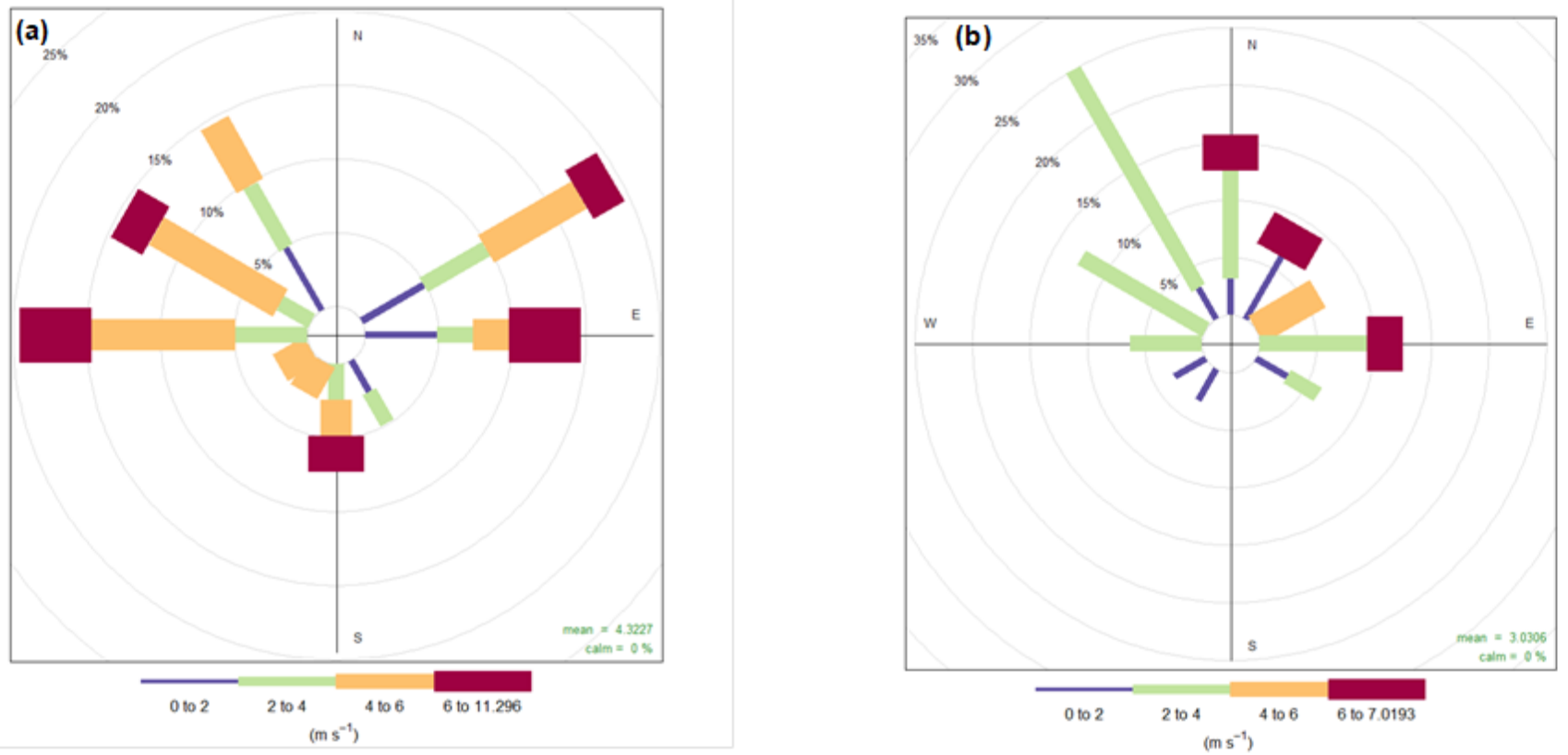
Figure 8

Frequency distribution of mean wind directions and wind forces (ms-1) in the period 90 min before to 90 min after curlew departure (a) and arrival (b).
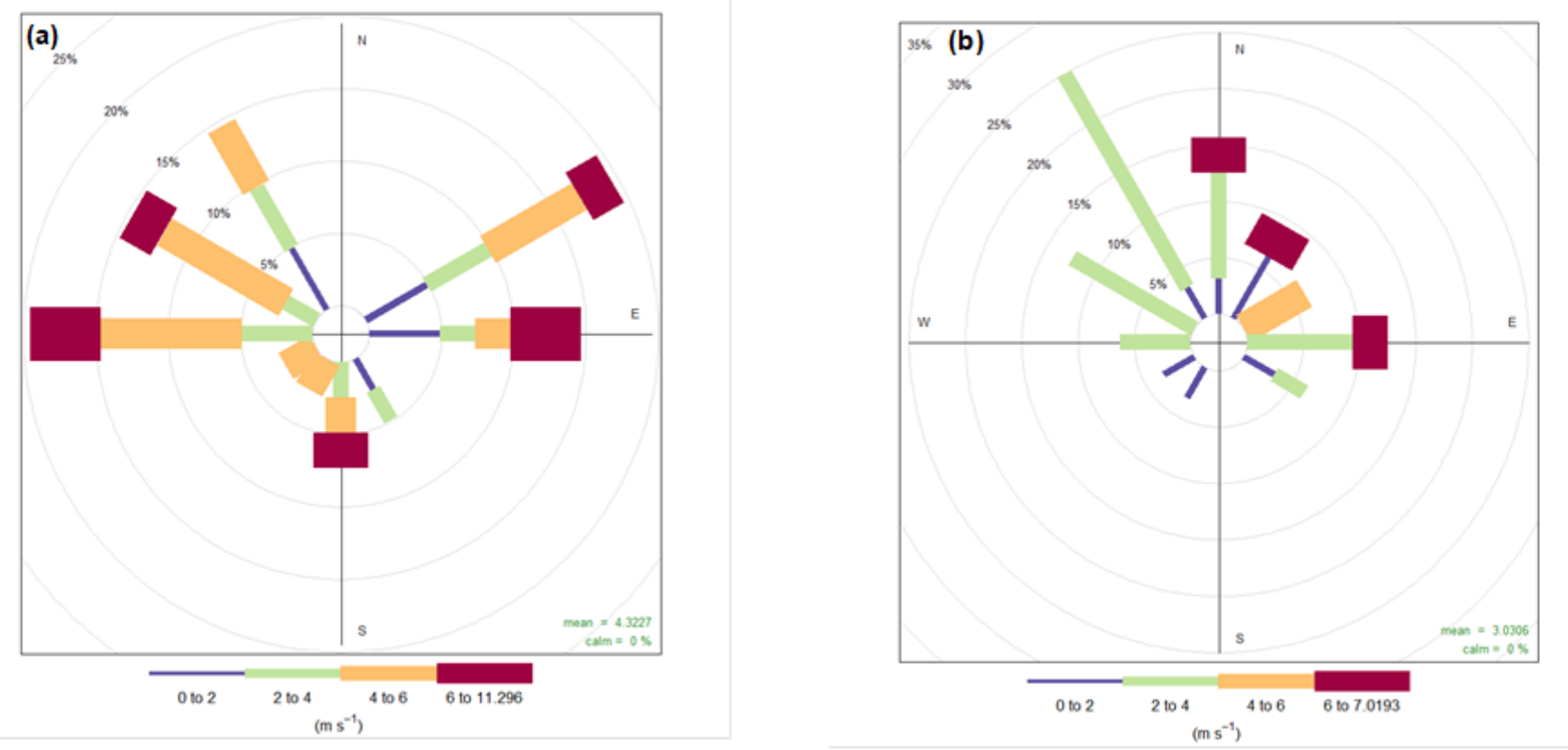

\section{Figure 8}

Frequency distribution of mean wind directions and wind forces (ms-1) in the period 90 min before to 90 min after curlew departure (a) and arrival (b). 


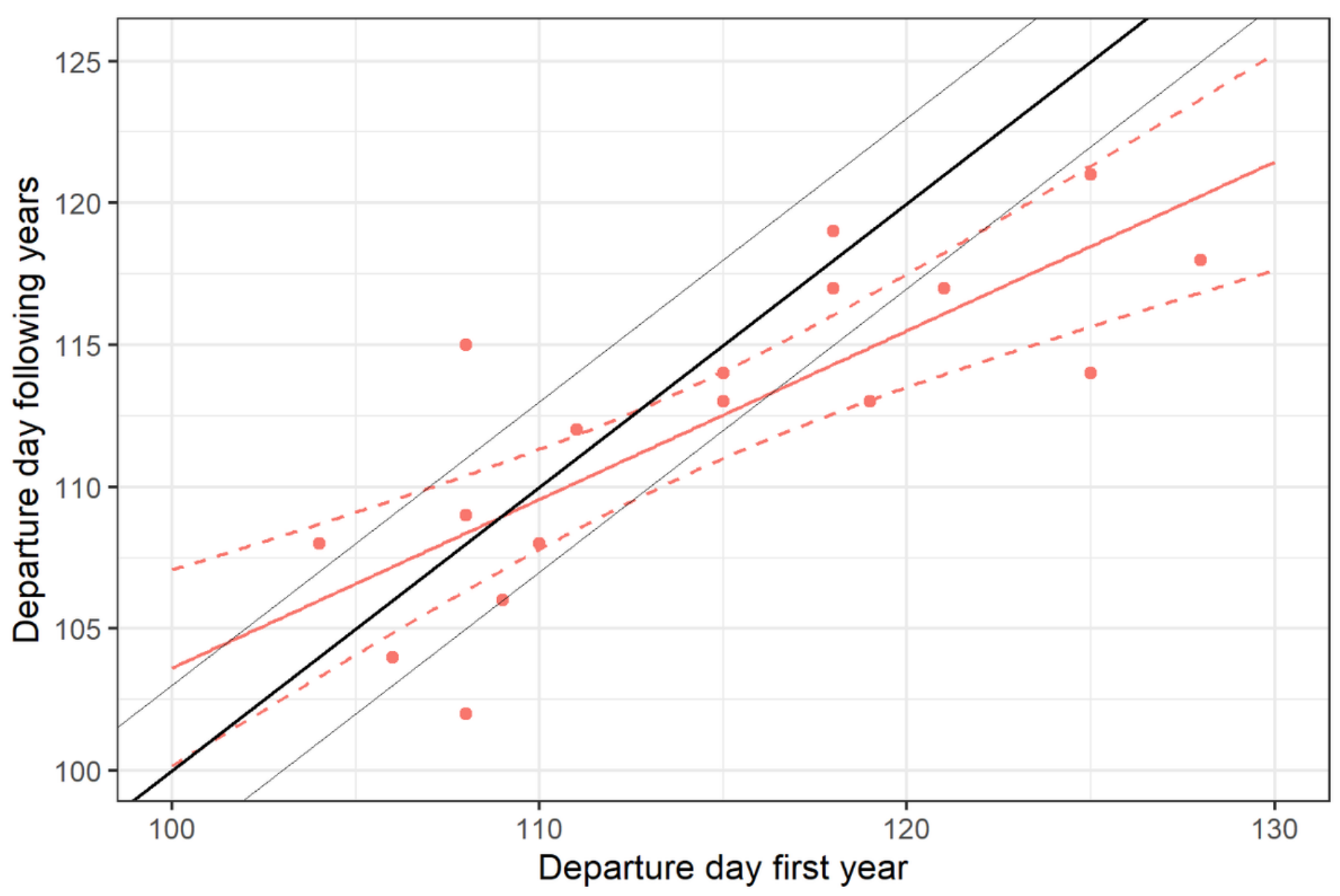

Figure 9

Departure days in successive years. Red solid line: model curve; dashed lines: 95\% confidence intervals, bold black line indicates 1:1 relationship, thin black lines depict departure days 3 days before or after this. 


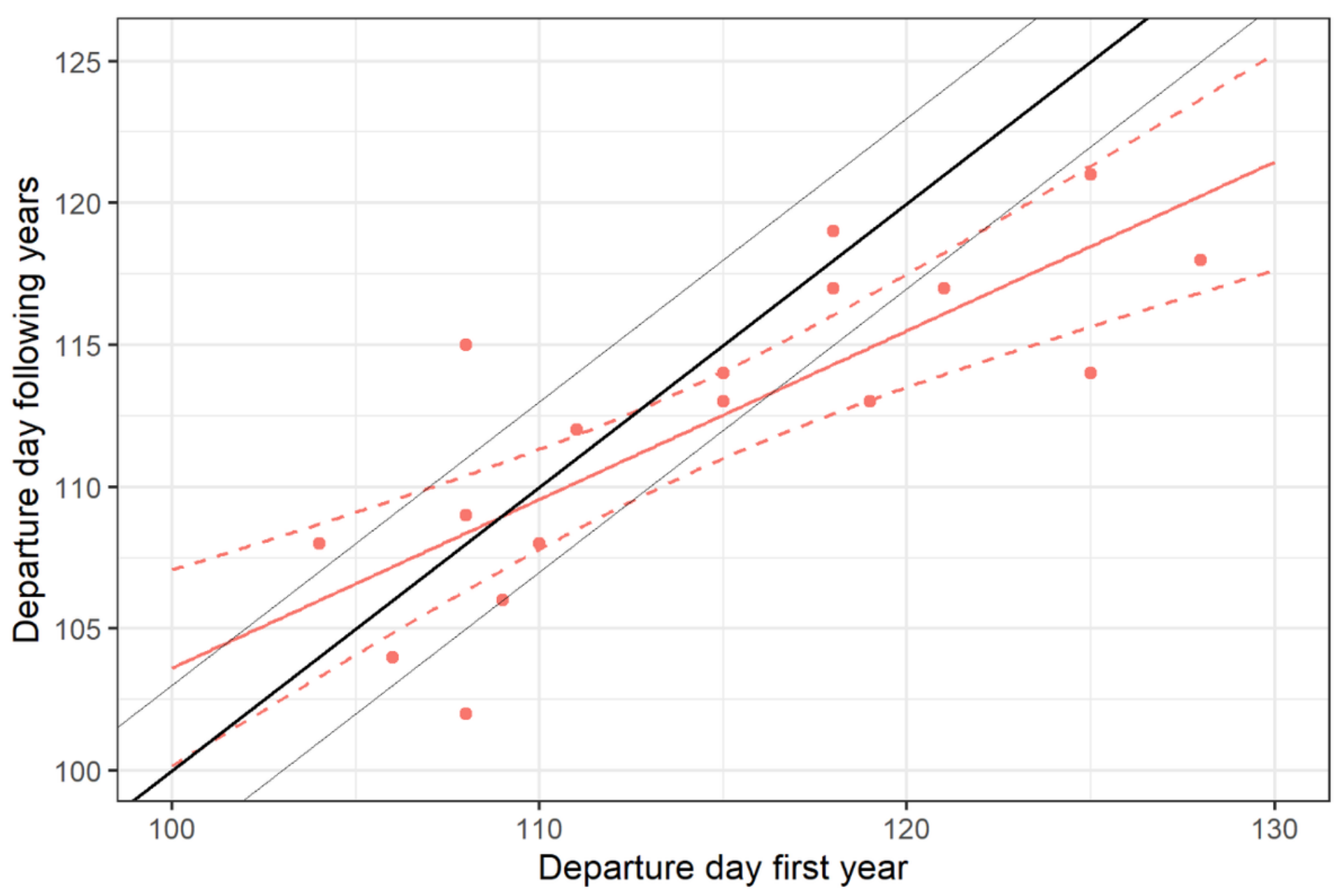

Figure 9

Departure days in successive years. Red solid line: model curve; dashed lines: 95\% confidence intervals, bold black line indicates 1:1 relationship, thin black lines depict departure days 3 days before or after this.

\section{Supplementary Files}

This is a list of supplementary files associated with this preprint. Click to download.

- Supplement201028clean.docx

- Supplement201028clean.docx 